\title{
Regeneration of Cochlear Efferent Nerve Terminals after Gentamycin Damage
}

\author{
Anne K. Hennig and Douglas A. Cotanche \\ Department of Anatomy and Neurobiology, Boston University School of Medicine, Boston, Massachusetts
}

Chickens recover auditory function after hair cell loss caused by ototoxic drug damage or acoustic overstimulation, indicating that mechanisms exist to reestablish appropriate neuronal connections to regenerated hair cells. However, despite similar hair cell regeneration times, hearing recovery takes substantially longer after aminoglycoside than after sound damage. We have therefore begun examining damage and regeneration of efferent nerve terminals by immunolabeling whole-mount cochleae for differentially localized synaptic proteins and by visualizing the distribution of label with confocal microscopy. In undamaged cochleae, the synaptic proteins synapsin and syntaxin show similar distribution patterns corresponding to the large cup-like terminals on short hair cells. After gentamycin administration, these terminals are disrupted as hair cells are lost, leaving smaller, more numerous synapsin-reactive structures in the sensory epithelium. Syntaxin reactivity remains associated with the extruded hair cells, indicating that the presynaptic membrane is still attached to the postsynaptic site. In contrast, after sound damage, both synapsin and syntaxin reactivity are lost from the epithelium with extruded hair cells. As regenerated hair cells differentiate after gentamycin treatment, the synapsin labeling associated with cup-like efferent endings reappears but is not completely restored even after $60 \mathrm{~d}$ of recovery. Thus, efferent terminals are reestablished much more slowly than after sound damage (Wang and Raphael, 1996), consistent with the prolonged loss of hearing function. This in vivo model system allows comparison of axonal reconnection after either complete loss (sound damage) or partial disruption (gentamycin treatment) of axon terminals. Elucidating the differences in recovery between these injuries can provide insights into reinnervation mechanisms.

Key words: regeneration; cochlear efferent innervation; synapsin; axon terminal repair; hair cell innervation; aminoglycoside ototoxicity
Structural and functional regeneration of the chick auditory organ the basilar papilla (BP) has been extensively documented (Cotanche, 1987; Cruz et al., 1987; McFadden and Saunders, 1989; Tucci and Rubel, 1990; for review, see Cotanche et al., 1994, 1997). Research efforts have focused mainly on the details of hair cell regeneration, however. The fate of nerve terminals that synapse on hair cells has not been examined in detail, although appropriate reinnervation of regenerated hair cells is crucial to reestablishing hearing function. Recently described differences in efferent terminal damage after acoustic or ototoxic drug-induced hair cell loss (Ofsie et al., 1997) suggest a basis for the observed discrepancies in functional recovery times. The present studies further investigate the fate of efferent nerve terminals in cochleae after gentamycin treatment.

Innervation of the BP of the chick cochlea is analogous to that of the mammalian organ of Corti. Tall hair cells (which correspond to inner hair cells) receive the majority of afferent con-

Received Oct. 20, 1997; revised Feb. 12, 1998; accepted Feb. 18, 1998.

This work was supported by National Institutes of Health Grants RO1-DC01689 and 5T32 NS07152-18 and by funding from the National Organization for Hearing Research and the American Hearing Research Foundation. We thank Andrew Czernik for the generous gift of the synapsin antibody, Frank Schottler for assistance with statistical analyses and comments on this manuscript, Liz Messana for assistance in preparing the confocal images used for the figures, Mark Warchol for helpful and supportive discussions, and Julie Sandell and D. Kent Morest for critically reviewing this manuscript.

Correspondence should be addressed to Dr. Douglas A. Cotanche, Department of Otolaryngology and Communication Disorders, The Children's Hospital, 300 Longwood Avenue, Boston, MA 02115.

Dr. Hennig's present address: Central Institute for the Deaf, 818 South Euclid Avenue, St. Louis, MO 63110-1549.

Copyright $(\odot 1998$ Society for Neuroscience $\quad 0270-6474 / 98 / 183282-15 \$ 05.00 / 0$ nections, whereas short hair cells (which correspond to outer hair cells) receive primarily efferent connections (Tanaka and Smith, 1978; Whitehead and Morest, 1981, 1985; Fischer, 1992). Prolonged or intense sound exposure damages short hair cells at a frequency-specific location (Cotanche et al., 1997), whereas ototoxic drugs target both tall and short hair cells at the proximal end of the BP (Epstein and Cotanche, 1995; Janas et al., 1995). Thus, hair cells with predominantly efferent innervation are sensitive to both types of damage. We are therefore seeking to gain insights into reinnervation mechanisms associated with hair cell regeneration by investigating the fate of the efferent terminals.

Antibodies against synaptic components localized to particular sites within the synaptic terminals (Sudhof, 1995; Bauerfeind et al., 1996; Martin, 1997) are used here to follow changes in efferent terminal structure. The protein synapsin anchors vesicles to cytoskeletal elements, regulating their availability for docking to receptors in the presynaptic plasma membrane (Greengard et al., 1993). Syntaxin is one component of these receptors; vesicle binding initiates neurotransmitter release (Bennett et al., 1992). An antiserum to synapsin, which is specific for efferent terminals and does not label hair cells in the chick BP (Zidanic and Fuchs, 1996), has been used to follow efferent reinnervation after sound damage (Wang and Raphael, 1996). Cup-like efferent terminals on short hair cells are affected differently after sound or aminoglycoside treatment. Synapsin immunoreactivity disappears completely from the BP after sound damage but is redistributed as smaller "blobs" after gentamycin treatment (Ofsie et al., 1997). To further characterize gentamycin effects on efferent terminals, we compare synapsin and syntaxin localization in gentamycindamaged cochleae and follow synapsin reactivity patterns during 


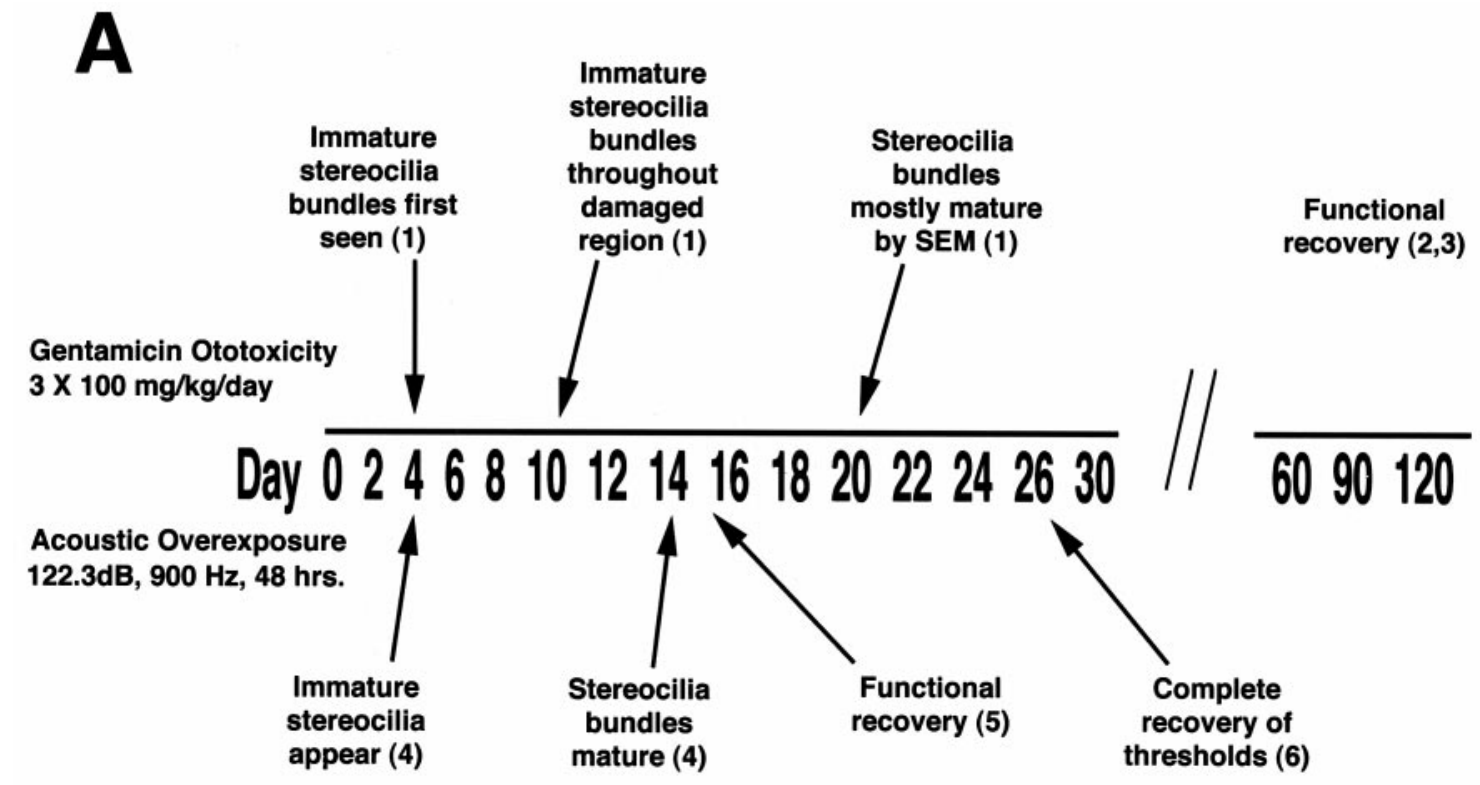

\section{B}

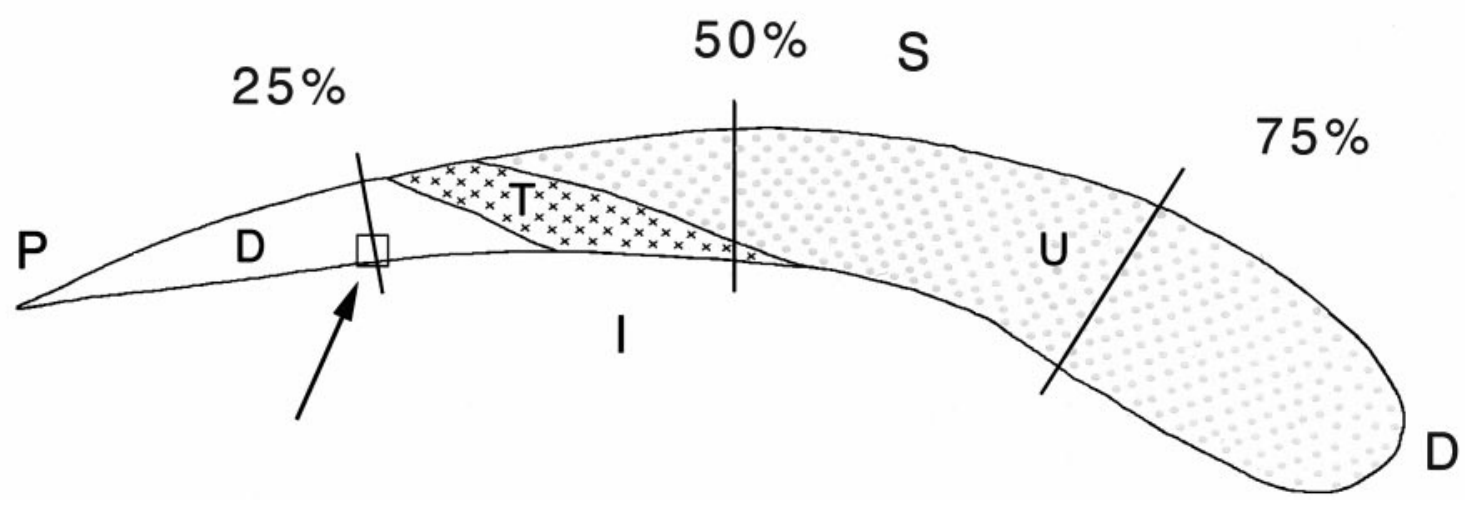

Figure 1. Characteristics of the $3 \mathrm{~d}$ gentamycin treatment protocol. $A$, Schematic diagram of the time course of gentamycin and sound damage. Chicks receive three consecutive daily injections of gentamycin at $100 \mathrm{mg} / \mathrm{kg}$ or exposure to a $900 \mathrm{~Hz}, 122.3 \mathrm{~dB}$ pure tone for $48 \mathrm{hr}$. The time of the first injection or the onset of the tone defines time 0 for the experiment, and subsequent time points are designated in hours or days after the onset of the treatment. For example, the second gentamycin dose is given at $24 \mathrm{hr}(1 \mathrm{~d})$ AOI. The morphological features of hair cell regeneration reported in the literature are noted with arrows at the appropriate time points (1, Epstein and Cotanche, 1995; Janas et al., 1995; 2, Tucci and Rubel, 1990; Girod et al., 1991; Salvi et al., 1994; 3, functional recovery has not been determined for short courses of gentamycin administration; 4, Stone and Cotanche, 1992; 5, McFadden and Saunders, 1989 (responses measured in the cochlear nucleus); Saunders et al., 1992 (evoked potentials); 6, Adler et al., 1993). B, Schematic diagram of a cochlea from a bird treated according to the $3 \mathrm{~d}$ gentamycin injection protocol. Proximal $(P)$ and distal $(D$ on the right) ends and superior $(S)$ and inferior $(I)$ edges of the BP are indicated, and lines representing 25, 50, and $75 \%$ of the length from the proximal tip are shown. The BP can be divided into three regions based on the amount of gentamycin damage; the proximal tip is completely denuded of all hair cells $(D$ on the left), the distal half appears undamaged $(U)$, and between these is a transition zone $(T)$ containing hair cells that remain in the epithelium but show some evidence of damage such as cell shape disruptions and stereocilia abnormalities. The standard region used for statistical determinations is indicated by the arrow.

regeneration to determine whether the altered morphology is associated with a delay in efferent terminal recovery.

\section{MATERIALS AND METHODS}

Gentamycin treatment and tissue preparation. Chicks $(n=78)$ were obtained from SPAFAS, Inc. (Preston, CT) at $12 \mathrm{~d}$ after hatching and housed in the animal care facility at the Boston University medical campus. All animal treatment procedures were approved by the Boston University School of Medicine Institutional Animal Care and Use Committee.
For studies examining efferent terminal damage and regeneration after gentamycin treatment, 48 12-15-d-old chicks were treated according to the protocol of Epstein and Cotanche (1995); 12 more chicks were tested in parallel as undamaged control birds. Three consecutive daily subcutaneous injections of gentamycin at $100 \mathrm{mg} / \mathrm{kg}$ were given, with the first injection defining time 0 after the onset of injections (AOI). By this method, day 1 AOI begins $24 \mathrm{hr}$ after the first injection (Fig. 1A). The chicks were allowed to recover for various lengths of time; in the first series of four experiments, 12, 12, and 6 birds were examined on days 4 , 10 , and 28 AOI, respectively, and the remaining 12 were examined on 
days 2,3 , and 5 to confirm the pattern of hair cell loss reported previously (Epstein and Cotanche, 1995). Because morphology had not completely returned to normal by $28 \mathrm{~d}$, another experiment was performed in which six birds on day 60 AOI and three age-matched untreated control birds were compared.

Four chicks were examined immediately after a $24 \mathrm{hr}$ exposure to a 900 $\mathrm{Hz}, 122.3 \mathrm{~dB}$ pure tone, according to the protocol of Cotanche et al. (1995). These sound-exposed cochleae were used to determine the presence of synapsin and syntaxin in the efferent terminals associated with extruded hair cells. Hair cell extrusion and regeneration follow a similar progression after either form of damage (for summary, see Cotanche et al., 1997).

To see whether regeneration of sound-damaged efferent terminals was delayed in the presence of gentamycin, we administered gentamycin to birds that had just received acoustic overstimulation and then compared the extent of efferent terminal regeneration at 12 or $16 \mathrm{~d}$ after the onset of sound exposure with birds that had been sound-exposed in parallel but had not received gentamycin. Twelve chicks were exposed to a $900 \mathrm{~Hz}$, $122.3 \mathrm{~dB}$ pure tone for $48 \mathrm{hr}$ (Cotanche et al., 1995). Eight of these received a full course of gentamycin, beginning immediately after removal from the sound chamber; the other four were examined in parallel for efferent terminal regeneration after sound damage alone. Four additional birds received only gentamycin. To confirm the extent of gentamycin damage and to establish that gentamycin did not increase the extent of the sound-damaged area, we examined on day 6 after the onset of sound exposure [4 d AOI of gentamycin ( $4 \mathrm{~d}$ AOI gentamycin)] two birds that had received both sound and gentamycin and one bird that was treated only with gentamycin.

Chicks were killed by intraperitoneal injection of Ketaset (Fort Dodge Laboratories, Fort Dodge, IA). The cochleae were quickly dissected, and the tegmentum vasculosum and lagena were removed in chilled, aerated HEPES-buffered Hanks balanced salt solution (Life Technologies, Grand Island, NY) with 4 mm sodium bicarbonate. Cochleae were then fixed by immersion for 20 min in $4 \%$ paraformaldehyde in PBS.

Antibody staining. Rabbit anti-synapsin Ia/IIa antiserum G304 was kindly supplied by Andrew Czernik of The Rockefeller University and was used at a 1:5000 dilution. This antiserum has been shown previously to recognize only efferent axon terminals in the chick BP (Zidanic and Fuchs, 1996; Ofsie et al., 1997). Synapsin I has also been reported in both lateral and medial efferent terminals in the mammalian organ of Corti (Eybalin and Renard, 1997). Monoclonal anti-syntaxin antibody (Sigma, St. Louis, MO) was used at 1:2000 dilution. In undamaged BP, the labeling pattern of this antibody is similar to that of the synapsin antiserum (see Fig. 2) and shows the expected pattern of bouton and cup-like efferent terminals. To the best of our knowledge, this antibody has not been tested in the mammalian organ of Corti. FITC-conjugated goat anti-rabbit IgG and goat anti-mouse IgG (Jackson ImmunoResearch, West Grove, PA) were used as secondary antibodies at a 1:50 dilution. All antibodies were diluted in PBS with $3 \%$ BSA and $0.2 \%$ Tween 20.

Fixed whole cochleae were washed three times for 10 min each in PBS, permeabilized $10 \mathrm{~min}$ in $1.0 \%$ (for synapsin) or $0.1 \%$ (for syntaxin) Triton X-100, washed twice more in PBS, and blocked with $10 \%$ goat serum diluted in PBS for $30 \mathrm{~min}$ at room temperature. Samples were incubated in diluted primary antibody for either $2 \mathrm{hr}$ at room temperature or overnight at $4^{\circ} \mathrm{C}$. After three 10 min washes in PBS, the samples were incubated in diluted secondary antibody for $2 \mathrm{hr}$ at room temperature. After two more washes in PBS, samples were stained for F-actin by incubating $30 \mathrm{~min}$ in 1:300 rhodamine-phalloidin (Molecular Probes, Eugene, OR) in PBS, washed three more times, and mounted on microscope slides with $0.1 \%$ p-phenylenediamine (Sigma) in $90 \%$ glycerol. As a reagent control, undamaged cochleae were incubated in diluent with no primary antibody and then treated in parallel with the test cochleae.

For cryostat sections, cochleae were fixed as for whole mounts and then infiltrated through 5, 15, and $20 \%$ sucrose solutions, embedded in $20 \%$ sucrose and $7.5 \%$ gelatin, flash-frozen in 2-methylbutane chilled on dry ice, and stored at $-80^{\circ} \mathrm{C}$ until sectioning. Sections were mounted on chrom-alum-subbed glass slides, warmed to $37^{\circ} \mathrm{C}$, washed twice with PBS at $37^{\circ} \mathrm{C}$, and then stained as for whole mounts. Before they were mounted, stained sections were incubated in $0.1 \mu \mathrm{g} / \mathrm{ml} \mathrm{4,6-diamidino-2-}$ phenylindole (DAPI) to label nuclei.

Microscopy and analysis. Samples were initially evaluated and photographed at low magnification using a Zeiss Axioskop (Carl Zeiss Inc., Thornwood, NY). Confocal scanning laser microscopy was performed on a Leica confocal laser scanning microscope equipped with epifluores- cence optics (Leica Lasertechnik GmbH, Heidelberg, Germany). Digital images of a compressed Z-series of scans through the entire thickness of the $\mathrm{BP}$ were made using a $25 \times$ or $50 \times$ water immersion objective. Images used for the figures were processed with Adobe Photoshop and Pagemaker software programs (Adobe Systems, Inc., Mountain View, CA). For statistical analysis, pairs of $50 \times$ confocal micrograph images showing rhodamine-phalloidin and synapsin-FITC labeling were taken from three day 4 AOI, six day $10 \mathrm{AOI}$, five day $28 \mathrm{AOI}$, four day $60 \mathrm{AOI}$, and eight control samples, at a position bordering the abneural edge and $20-30 \%$ from the basal end of the BP. Within the image area $(100 \times 100$ $\mu \mathrm{m})$, the total number of phalloidin-reactive stereocilia bundles, cupshaped synapsin-labeled profiles, and the smaller synapsin-reactive blobs were enumerated. Those structures contacting the bottom and right-hand borders of the image were included in counts, but those contacting the top or left-hand borders were not included. This method of counting occasionally resulted in, for example, a stereocilia bundle being counted, whereas the cup-shaped terminal structure on the same cell was excluded. The surface areas were measured for all hair cells bordered by completely visible junctional complexes. Phalloidin staining was too weak in one of the $28 \mathrm{~d}$ samples for assessment of hair cell surface areas. Means and SEMs were determined for each set of counts, and statistical analyses were performed using SigmaStat (Jandel Scientific, San Rafael, CA). One-way ANOVA was used to examine overall differences for each of the structure density or cell surface area measurements, and Tukey post hoc tests were used to evaluate differences between groups at the various time points after gentamycin treatment. Values are presented in the text as the mean \pm 1 SEM. For surface area measurements, the coefficients of variation of the control or treatment group samples were compared using a Mann-Whitney rank sum test.

\section{RESULTS}

Efferent terminals on short hair cells are damaged by both sound and aminoglycoside antibiotics. These terminals represent the axonal endings of CNS neurons; they contain the same synaptic machinery as motoneurons and other well-studied neuronal types (Sudhof, 1995; Bauerfeind et al., 1996; Martin, 1997). Because many of these synaptic release proteins are not present within auditory hair cells (Zidanic and Fuchs, 1996; Eybalin and Renard, 1997; Ofsie et al., 1997; A. K. Hennig, unpublished observations), whole cochleae can be labeled with antibodies against synaptic constituents to visualize efferent terminals and counterstained with phalloidin to label hair cell stereocilia and other actin-containing structures, permitting visualization of different functional zones within efferent terminals as well as distribution of the terminals relative to hair cells.

In undamaged cochleae, phalloidin-labeled stereocilia bundles are distributed in a regular array across the apical surface of the BP (Fig. 2A,E). The edges of the hair cell apical surfaces are demarcated by phalloidin labeling of the juctional complexes with the adjacent supporting cells. On average, $70 \pm 2.9$ hair cells with surface areas of $\sim 133 \pm 3.5 \mu \mathrm{m}^{2}$ are present within the $100 \times 100$ $\mu \mathrm{m}$ area examined (Fig. 3). Two types of efferent terminals are present: large cup-shaped calyces that surround the basal surface of short hair cells in the inferior half of the BP and small boutons associated with both the tall hair cells overlying the superior cartilaginous plate and the hyaline cells adjacent to the inferior edge of the BP (Fischer, 1992). Antibodies against synapsin label the "reserve pools" in which mature synaptic vesicles are stored within both types of terminals (Greengard et al., 1993; Zidanic and Fuchs, 1996; Martin, 1997). In a confocal image constructed by compressing a series of optical sections taken along the axis perpendicular to the plane of the BP (looking down through the hair cell body), label within the cup-shaped terminals appears as an elongated, concave "cup-like" or "dumbbell" profile (Fig. 2B). Within the inferior half of the BP, there is essentially one cupshaped profile for each hair cell, and no smaller bouton-like terminals are seen (Fig. 3). Synapsin label is rarely seen in nerve 

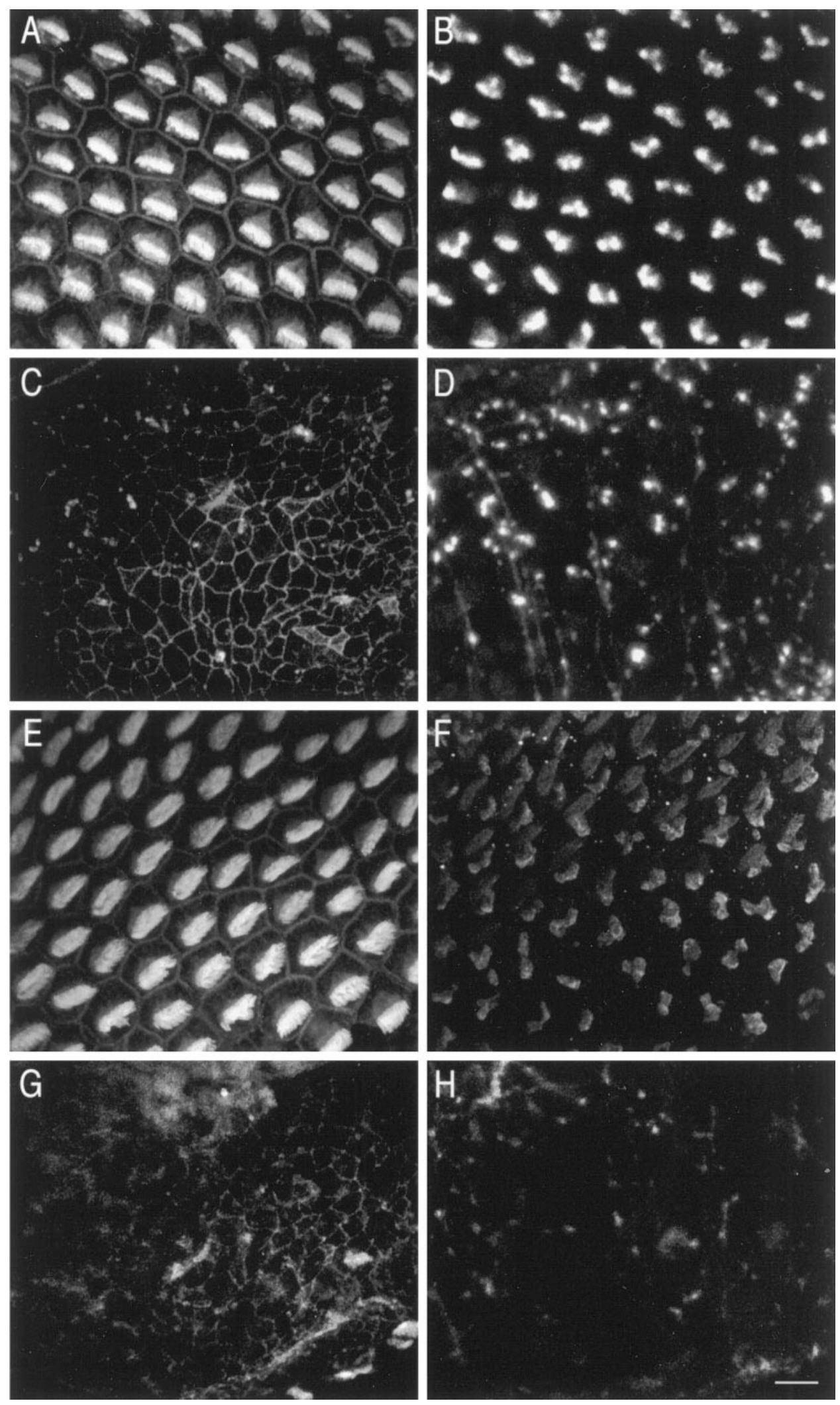

Figure 2. Phalloidin versus synapsin or syntaxin reactivity. Confocal images were taken at the inferior edge $25 \%$ of the length from the proximal end of control or of $4 \mathrm{~d}$ AOI gentamycin cochleae. $A$, Phalloidin reactivity in an undamaged cochlea shows the regular array of stereocilia bundles and the junctional complexes between hair cells and supporting cells. $B$, Synapsin reactivity in the same region shown in $A$ is found in a cup-shaped structure enclosing the base of each short hair cell. Compression of optical sections taken along the $z$-axis (perpendicular to the plane of the BP, looking down through the hair cell into the bowl of the cup-like terminal) results in a concave, elongated immunoreactive profile (Ofsie et al., 1997). No reactivity of nerve fibers is evident in undamaged cochleae. $C$, Phalloidin reactivity in the same region of a gentamycin-treated cochlea at $4 \mathrm{~d}$ AOI shows the absence of stereocilia bundles, indicating the complete loss of mature hair cells. Junctional complexes between cells are still evident. $D$, Synapsin reactivity in the same region as in $C$ shows essentially complete loss of the large cup-shaped profiles from the inferior half of the $\mathrm{BP}$ and their replacement with smaller, round or oval profiles of irregular size scattered throughout this region. Also note the synapsin reactivity in transverse nerve fibers (running vertically in this panel). E, Phalloidin reactivity in another undamaged cochlea is shown. $F$, Syntaxin reactivity in the same region as in $E$ shows a pattern of profiles similar to those seen with synapsin. (Some bleed-through phalloidin reactivity shows at the top of the panel.) Syntaxinreactive nerve fibers, although not present in this sample, are sometimes seen in control samples. $G$, Phalloidin reactivity in another $4 \mathrm{~d}$ AOI gentamycin cochlea again shows the loss of hair cells. $H$, Syntaxin reactivity in the same region as in $G$ shows markedly decreased syntaxin reactivity within the BP compared with the undamaged controls (compare with $F$ ). Scale bar, $10 \mu \mathrm{m}$.

fibers in undamaged cochlea whole mounts. These results are in agreement with previous reports (Wang and Raphael, 1996; Zidanic and Fuchs, 1996; Ofsie et al., 1997). A similar staining pattern is seen with antibodies against syntaxin (Fig. $2 F$ ). These patterns correspond with the distribution of efferent terminals on hair cells determined by serial section transmission electron microscopy (TEM) (Fischer, 1992). Neither synapsin nor syntaxin reactivity is seen within hair cells anywhere in the BP.

Most studies of aminoglycoside damage have used $10 \mathrm{~d}$ drug administration protocols modeled on treatment regimens recom- 
Figure 3. Mean hair cell density (number of stereocilia bundles regardless of size), cup-like synapsinreactive profiles, blob and bouton-like synapsinreactive profiles, and mean hair cell surface areas (in square micrometers) were determined within a $100 \times$ $100 \mu \mathrm{m}^{2}$ confocal image taken at the inferior edge $20-30 \%$ of the length from the proximal end of the BP of each sample examined. Images were obtained from five untreated controls, three samples at $4 \mathrm{~d}$ AOI, six samples at $10 \mathrm{~d}$ AOI, and five samples at $28 \mathrm{~d}$ AOI in one series of experiments and from four samples at $60 \mathrm{~d}$ AOI and three untreated age-matched controls in a second set of experiments. Error bars indicate 1 SEM from the mean, an asterisk (*) indicates groups that differ from the appropriate control group at $p<0.01$, and a dagger $(\dagger)$ indicates a difference of $p<0.05$; $n d$, not determinable because of the absence of hair cells. These data were interpreted as follows. Hair cells are essentially completely absent from $4 \mathrm{~d}$ AOI samples. Approximately two-thirds of the number of hair cells seen in control samples within the area measured have reappeared in the region examined by $10 \mathrm{~d}$ AOI. The number remains decreased in the $28 \mathrm{~d}$ samples compared with controls, but a further increase by $60 \mathrm{~d}$ AOI is consistent with a second wave of regenerating hair cells developing in these later samples. Cup-like endings are markedly decreased at $4 \mathrm{~d}$ AOI, increasing slightly in number at each of the later time points. The numbers are still significantly lower than control levels at $60 \mathrm{~d}$ AOI. Blob and bouton-like endings cannot be differentiated by the technique used for enumeration and so are classified together. Neither structure is seen in control samples within the region examined. At $4 \mathrm{~d}$ AOI, on average, 114 of the smaller profiles have replaced 68 cup-like endings, giving a ratio of 1.7 blobs per cup-like terminal lost. The number of blobs present in the sample area decreases slightly to $28 \mathrm{~d}$ AOI, but no further decrease is seen in the $60 \mathrm{~d}$ AOI samples. Hair cell surface areas are significantly smaller than that of controls at $10 \mathrm{~d}$ but have on average reached control levels by $28 \mathrm{~d}$. At $60 \mathrm{~d}$ AOI, the smaller mean hair cell areas relative to $60 \mathrm{~d}$ controls are consistent with a second wave of immature hair cells.

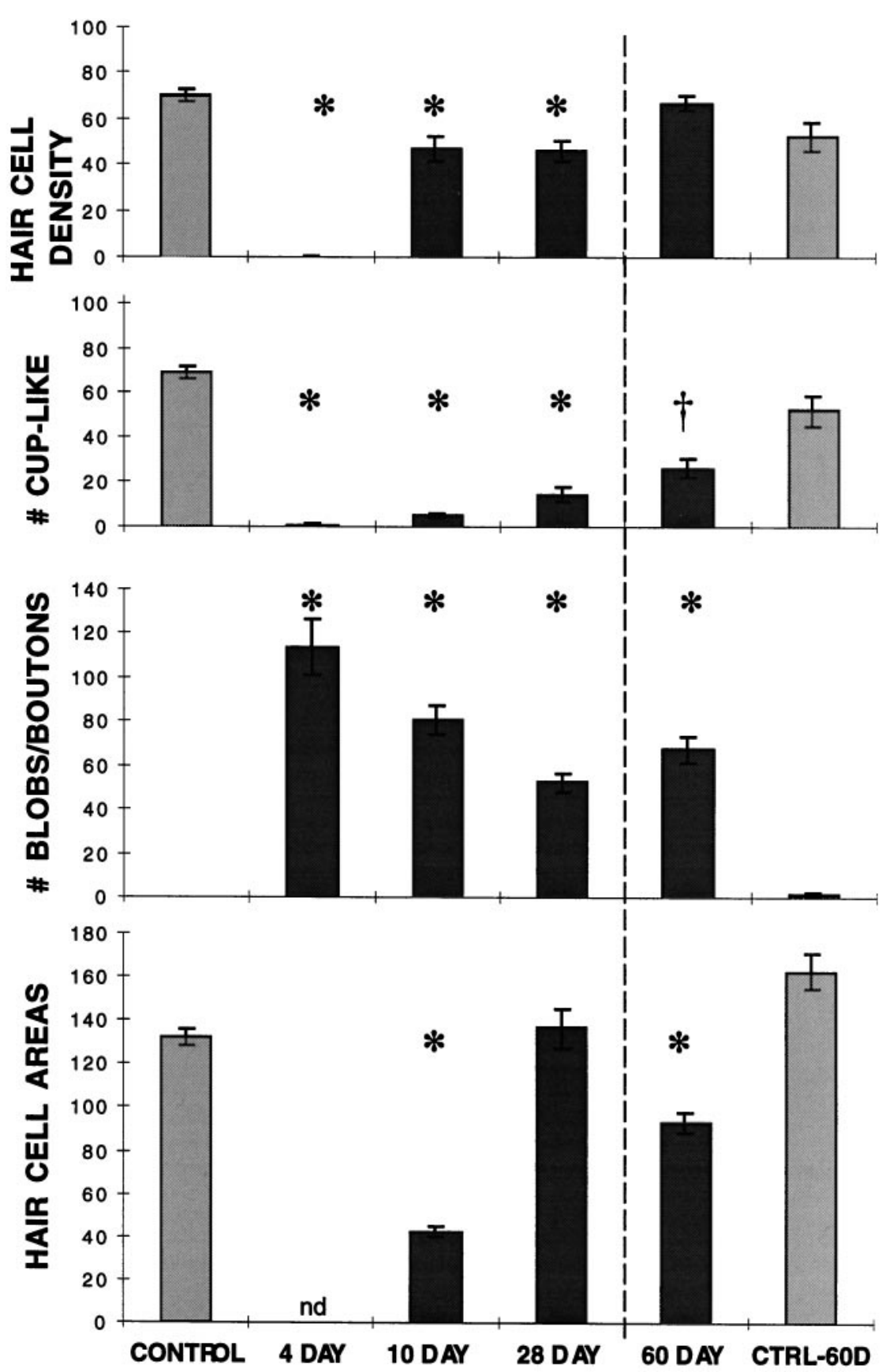

mended for these antibiotics, usually administered to newly hatched chicks. Our protocol uses a shorter course of gentamycin treatment in older birds for several reasons. Older birds are used to avoid complications attributable to potentially increased neuronal plasticity associated with postnatal sensory development (Cotanche and Sulik, 1985; Katayama, 1985; Tilney et al., 1986; Cotanche et al., 1987). We also want to separate damage effects from regeneration effects. Regeneration begins even when gentamycin is still being given in the chronic administration model (Duckert and Rubel, 1990; Janas et al., 1995). Furthermore, even after drug administration is terminated, continuing damage to the regenerated hair cells has been described with the longer treatment protocols (Duckert and Rubel, 1990). However, a singledose regimen shows highly variable damage patterns, particularly in older birds (Janas et al., 1995; Cotanche et al., 1997). The administration of a high dose of gentamycin over $3 \mathrm{~d}$ results in a predictable, reproducible amount of damage in birds older than $10 \mathrm{~d}$ of age (Epstein and Cotanche, 1995; Cotanche et al., 1997) (summarized in Fig. $1 B$ ).

In contrast to sound damage, which results in the loss of only a subset of hair cells within the damaged region, all hair cells in the proximal BP are highly sensitive to aminoglycoside toxicity. Using the $3 \mathrm{~d}$ gentamycin administration protocol, we found that hair cell damage is evident as early as day 2 AOI at the extreme proximal end of the BP. The area of hair cell loss expands toward the distal end of the cochlea over the next $3 \mathrm{~d}$ to encompass at least $25 \%$ of the length of the BP at the neural edge (shown schematically in Fig. $1 B$ ). Typically, the area of complete hair cell loss extends further along the inferior edge than along the superior edge and is separated from undamaged BP by a transition 
zone containing damaged hair cells with alterations in apical surface area and disrupted stereocilia arrays (Janas et al., 1995). In the present study, hair cell loss after gentamycin is detected as the disappearance of phalloidin-reactive stereocilia bundles from the BP (see Figs. $2 C, G, 5$ ). Taking into account the fact that the earliest regenerating stereocilia bundles detectable by scanning electron microscopy (sEM) do not stain with phalloidin (Lee and Cotanche, 1996), the present findings confirm the progression of hair cell damage and regeneration determined previously by sEM (Epstein and Cotanche, 1995).

In cochleae examined at $4 \mathrm{~d}$ AOI, when damage to the hair cells is still progressing distally along the length of the BP, the complete absence of phalloidin-reactive stereocilia bundles extends throughout the proximal $20 \%$ of the BP. In addition, staining with both synapsin and syntaxin reveals that essentially all of the large cup-like profiles are gone from this area (Figs. $2 D, H, 3$ ). In their place are smaller, round or oval synapsin-reactive blobs that are present at slightly less than twice the number of cup-shaped endings in the control samples. This suggests that the loss of one cup-shaped ending gives rise to more than one blob. Synapsin reactivity is also present in nerve fibers within the area of hair cell loss in the whole-mount samples (Fig. 2D). Such synapsinreactive nerve processes are unique to damaged areas in wholemount cochleae and are not seen either in undamaged areas of the same samples or in samples from untreated birds. Synapsin reactivity in cross-sections of the damaged area at $4 \mathrm{~d}$ AOI (Fig. 4) shows blobs at different depths within the BP but arranged in close proximity to the fibers that presumably led to terminals on hair cells.

The transition zone between the area of complete hair cell loss and the more distal undamaged areas of the BP has been examined in more detail in the $4 \mathrm{~d}$ AOI samples (Fig. 5). Because damage is still progressing apically at this time, the hair cells that appear intact at the distal edge of this zone would show signs of damage and/or be extruded from the epithelium if the bird had survived an additional day. The demarcation between the small synapsin-reactive blobs seen in areas of hair cell loss and the large cup-shaped profiles associated with normal cup-like terminals falls within this zone. Doomed hair cells are still associated with single cup-shaped terminal profiles (Fig. 5, asterisks). The first evidence of the morphological change in the synapsin-labeled structure from cup-shaped to blob occurs as the hair cell is being extruded from the BP. The contracted, thickened profiles (Fig. 5, arrowheads) and clusters of small blobs (Fig. 5, arrows) associated with some of the hair cells indicate that the cup-shaped terminals give rise directly to the blobs. This, together with the increased number of synapsin-reactive structures within the BP after hair cell loss, suggests that at least some of the terminals might be breaking apart.

To investigate this possibility further, we labeled cochleae with an antibody against syntaxin, one of the T-snare proteins in the presynaptic plasma membrane that form the receptor for synaptic vesicle docking (Sudhof, 1995; Bauerfeind et al., 1996; Martin, 1997). This allows us to follow the fate of that part of the terminal that is anchored in the synaptic space and in closest contact with the hair cell. In $4 \mathrm{~d}$ AOI gentamycin cochleae, syntaxin reactivity is markedly decreased in the areas of complete hair cell loss, although some reactivity in nerve fibers is seen (Fig. $2 H$ ). This reactivity in fibers becomes more apparent in areas proximal to the transition zone (data not shown), suggesting syntaxin may accumulate in damaged terminal processes after hair cell loss.

Damaged hair cells are often ejected from the BP and trapped
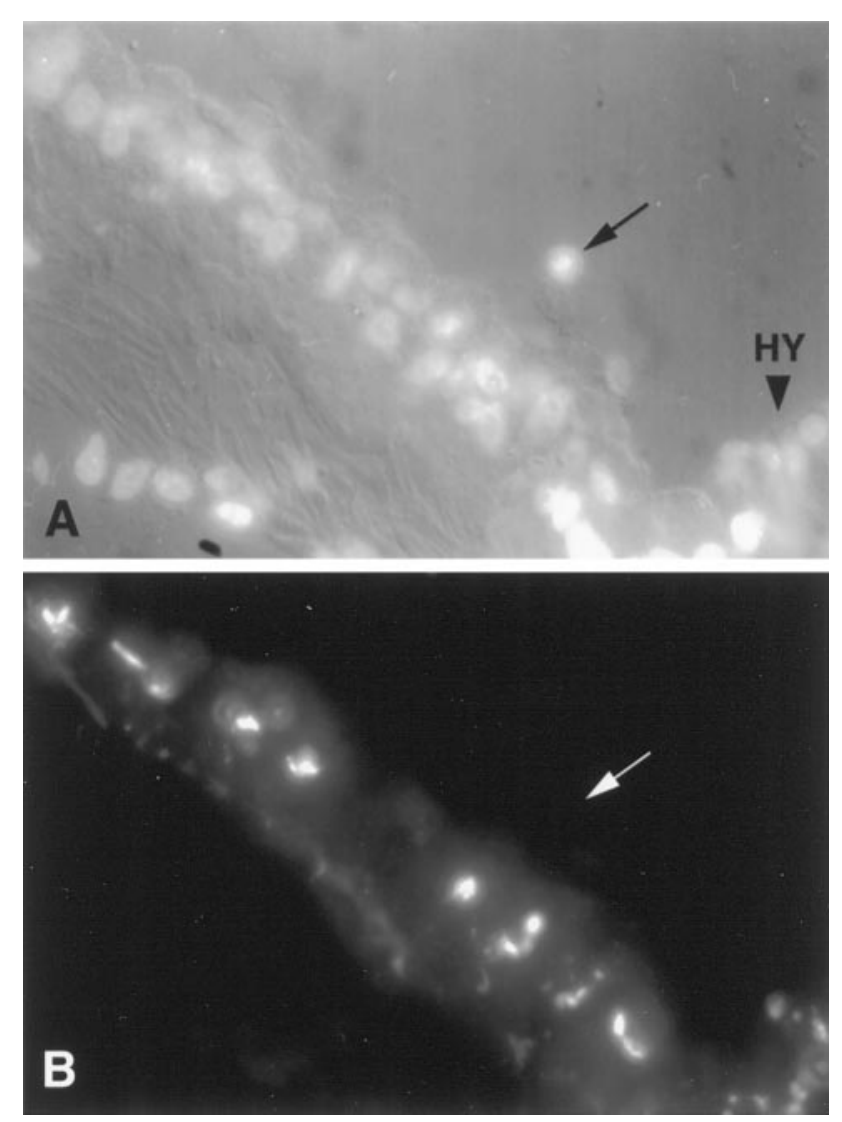

Figure 4. Cross-section through a $4 \mathrm{~d}$ AOI gentamycin cochlea. Cryostat sections of a $4 \mathrm{~d}$ AOI gentamycin cochlea immunolabeled with synapsin and counterstained with DAPI were examined to determine the distribution of the blobs within the BP. $A$, DAPI fluorescence superimposed on a Differential Interference Contrast image of the inferior edge of the BP and adjacent hyaline cells $(H Y)$. An extruded hair cell (arrow) with pyknotic nucleus can be seen above the plane of the BP. The lack of stereocilia bundles from the apical surface of the BP is consistent with the absence of hair cells in the gentamycin-damaged region. B, Synapsin immunoreactivity in the same field. Bright fluorescent blobs are seen approximately halfway between the apical and basal surfaces of the BP, often in close proximity to fibers emerging from the transverse nerve fiber bundles at the basal edge of the BP. Small bouton-like immunoreactive puncta can also be seen in the hyaline cell area. Note the lack of immunoreactivity associated with the extruded hair cell (arrow).

between the BP itself and the tectorial membrane (Epstein and Cotanche, 1995). In many 4 d AOI samples, extruded hair cells can be found under the tectorial membrane, outside the focal plane of the BP (see Fig. 4). Substantially more syntaxin than synapsin reactivity is associated with these extruded hair cells (Fig. 6 $A, C$ ). We conclude that the presynaptic plasma membrane of the efferent terminals is severed from the rest of the terminal and extrudes with the hair cells, whereas much of the synapsin reactivity from parts of the terminal containing cytoskeletal elements remains within the $\mathrm{BP}$ in the blobs. However, it is also possible that synapsin associated with the parts of the terminal remaining on extruded hair cells is either soluble and washes away or degrades before fixation of the tissue.

Hair cell extrusion occurs after sound overexposure as well (Cotanche et al., 1997). The complete absence of synapsinreactive structures from the BP after sound-induced hair cell loss (Wang and Raphael, 1996; Ofsie et al., 1997) suggests that the efferent terminals are severed from the nerve fibers and extruded 

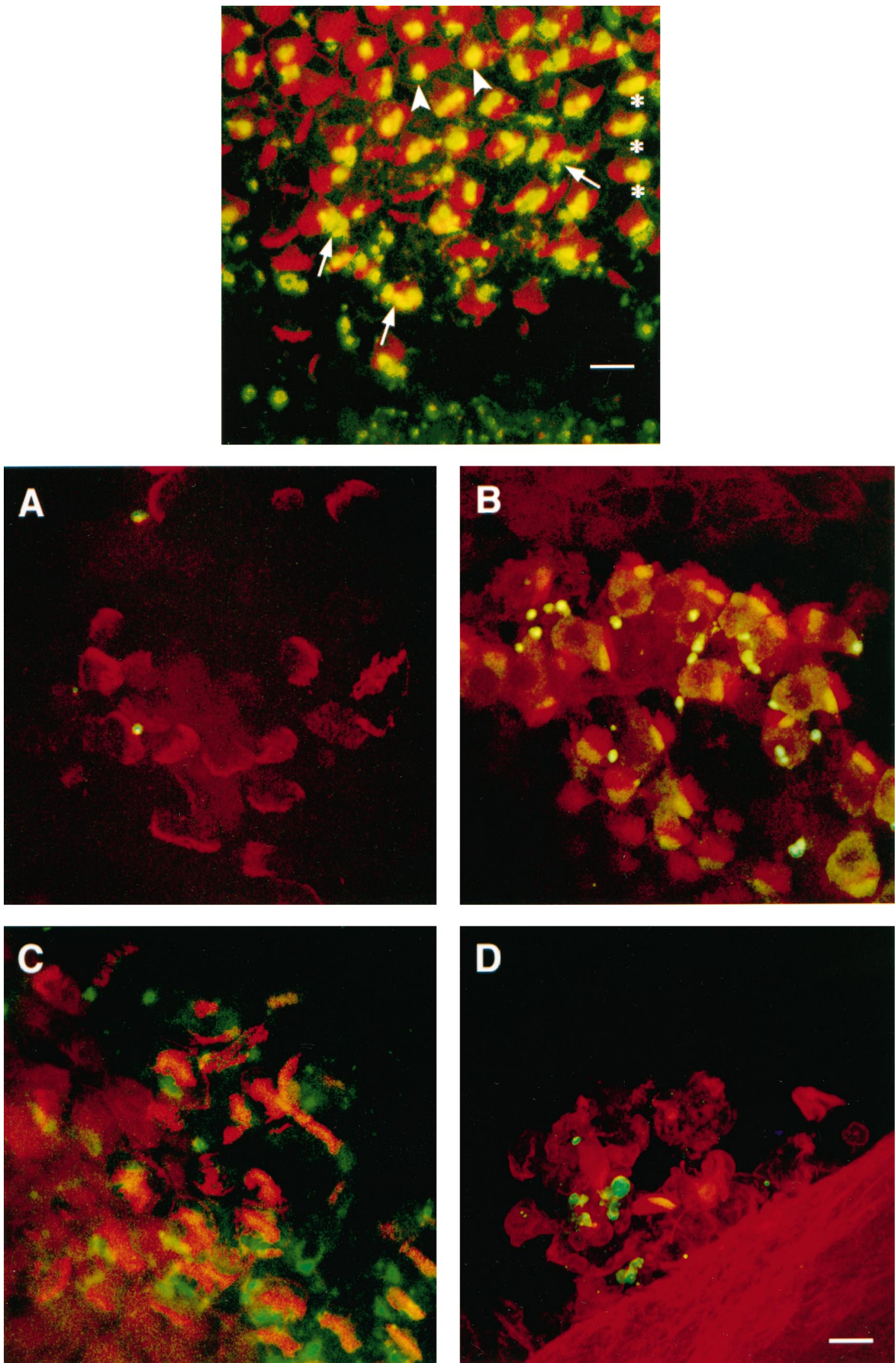

Figure 5. Top. The inferior BP in the transition zone, from a cochlea removed at $4 \mathrm{~d}$ AOI gentamycin, labeled for synapsin ( green) and F-actin (red). Yellow indicates overlap of the two labels in the compressed Z-series image (not necessarily colocalization in the sample). On the right, hair cells show relatively little sign of damage, and the associated synapsin-labeled terminals have large cup-shaped profiles (asterisks). As one moves from right to left, hair cell damage becomes progressively more evident as a disruption of the regular array of stereocilia. On the left, the absence of stereocilia bundles shows hair cell loss, and synapsin-labeled blob profiles are present singly or in small clusters. In the region where disordered stereocilia bundles show evidence of hair cell damage and extrusion, the cup-shaped terminals are being replaced by smaller, round or oval blob profiles. Figure legend continues. 


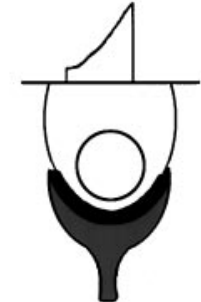

UNDAMAGED

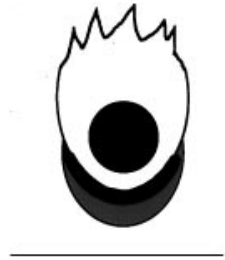

SOUND

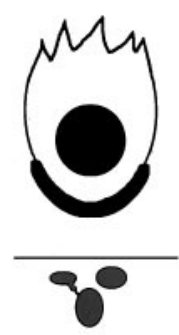

GENTAMICIN
Figure 7. Model for efferent terminal damage, based on the findings of these studies. In the undamaged BP, efferent terminals on short hair cells have syntaxin reactivity (black line) associated with the presynaptic plasma membrane adjacent to the hair cell and synapsin reactivity (gray area) localized more internally. After sound damage, the entire terminal structure remains attached to extruded hair cells, and no syntaxin or synapsin reactivity remains within the epithelium. In contrast, after gentamycin damage, the terminal breaks apart with the presynaptic membrane containing syntaxin reactivity remaining attached to extruded hair cells, whereas other fragments of the terminal containing synapsin reactivity remain within the BP. Synapsin reactivity in this case might also accumulate in axonal varicosities and/or be in the process of retrograde transport back to the neuronal cell body.

with the hair cells. We reasoned that both synapsin and syntaxin reactivity should be found in association with extruded hair cells in this case. When extruded hair cells in cochleae from soundexposed birds are examined, both synapsin and syntaxin reactivity are present as expected (Fig. 6B,D). Our interpretation of these findings is summarized in the model of efferent terminal damage presented in Figure 7.

Wang and Raphael (1996) report that most regenerating hair cells regain synapsin-reactive structures by $9 \mathrm{~d}$ after sound exposure, consistent with the timing of functional hearing recovery. To investigate the fate of efferent terminals after gentamycin damage for comparison, we examined synapsin-labeled structures and hair cell regeneration (assessed by phalloidin staining) at four time points after gentamycin treatment: day 4 AOI before evidence of hair cell regeneration is apparent by phalloidin staining, day 10 AOI when immature hair cells with small stereocilia bundles are evident throughout the damaged area, day 28 AOI when the morphology of the regenerating stereocilia is reaching mature dimensions, and day 60 AOI. For statistical analyses, paired confocal images of rhodamine-phalloidin and synapsinFITC staining patterns were taken at the abneural edge of the BP, $20-30 \%$ of the length from the basal end. From these images, the number of phalloidin-reactive stereocilia bundles (representing individual hair cells), cup-shaped synapsin-labeled profiles (presumably efferent synaptic terminals on short hair cells), and bouton or blob synapsin-labeled profiles are counted, and the cell surface area surrounding the stereocilia bundles is determined. The results are summarized in Figure 3. ANOVA shows that the density of hair cells, cup-shaped structures, and blob structures from all experimental treatment groups except day $60 \mathrm{AOI}$ differ significantly from that of undamaged controls at a level of $p<0.01$.

Quantitative analysis of undamaged control samples shows essentially one large cup-like ending per hair cell $(69.4 \pm 2.8$ cup-like endings per standard area compared with $70.4 \pm 2.9$ stereocilia bundles). The slight difference in the numbers results from the fact that the efferent terminal at the base of the hair cell is not always directly under the stereocilia bundle in the compressed series of confocal scans that make up each image, and so occasionally one is counted and the other excluded because of contact with the top or left border of the image (see Materials and Methods). No bouton terminals are seen on short hair cells of the inferior half of the BP, and no labeled blob structures are found in control cochleae. Quantitative analysis of $4 \mathrm{~d}$ AOI samples confirms the essentially complete loss of hair cells $(0.3 \pm 0.3)$ and cup-like endings $(1.3 \pm 0.9)$. A mean of $114.3 \pm 12.2$ blob structures is present, $\sim 1.7$ per cup-shaped terminal lost. These findings at day $4 \mathrm{AOI}$ are equivalent to comparable counts at the same position in day 5 AOI cochleae reported previously (Ofsie et al., 1997). This suggests that there is very little change in these parameters between 4 and $5 \mathrm{~d}$ AOI, even though damage is still progressing in more distal areas of the BP. Thus, the change in the number and shape of synapsin-containing structures occurs in association with damage and extrusion of hair cells but seems to stabilize once the hair cells are gone.

At day 10 AOI, immature stereocilia bundles are distributed throughout the proximal region of the BP from which all mature hair cells had been lost (Fig. 8A). However, the hair cell density within the area examined $(47.2 \pm 5.3)$ is significantly decreased relative to the same area in undamaged controls (70.4 $\pm 2.9 ; p<$ 0.01; Fig. 3). The apical surface area of these immature hair cells is variable but significantly smaller than that of controls (42.7 \pm 2.4 vs $132.8 \pm 3.5 \mu \mathrm{m}^{2}$, respectively; $p<0.01$; Fig. 3). The area surrounding these small hair cells is occupied by cells without stereocilia. Multiple actin bands can be seen between hair cells in these samples, in contrast to the single actin band separating adjacent hair cells in undamaged samples. Synapsin staining in this area reveals predominantly small, rounded blob structures (Fig. $8 B$ ), although these have decreased significantly in number from day 4 values $(81.2 \pm 6.9$ vs $114.3 \pm 12.2$, respectively; $p<$ 0.05 ; Fig. 3). Occasional small cup-shaped profiles are seen, although the number is not statistically different from the day 4 values. Increased synapsin staining of fibers is still evident at this time (Fig. $8 B$ ), and syntaxin staining was seen in both fibers and small blob or bouton-like structures within the damaged area (data not shown).

By day $28 \mathrm{AOI}$, although the stereocilia bundle orientation is

\section{$\leftarrow$}

Near the inferior edge of the BP in the lower half of the frame, cup-shaped structures are being replaced by clusters of small blobs (arrows). More superiorly, synapsin reactivity appears condensed into single large blobs (arrowheads). The synapsin-labeled bouton-type terminals at the bottom edge of the frame are associated with unlabeled hyaline cells at the inferior border of the BP. Scale bar, $10 \mu \mathrm{m}$.

Figure 6. Bottom. Extruded hair cells from gentamycin- or sound-damaged cochleae show evidence of associated efferent terminal components. $A$, Extruded hair cells from a 4 d AOI gentamycin cochlea stained with synapsin (green) and phalloidin (red) show very little synapsin reactivity. $B$, Extruded hair cells from a synapsin and phalloidin double-labeled cochlea taken from a chick exposed to a $900 \mathrm{~Hz}, 122.3 \mathrm{~dB}$ pure tone for $24 \mathrm{hr}$ show reactivity for both markers, indicating synapsin is still present. $C$, Extruded hair cells from a $4 \mathrm{~d}$ AOI gentamycin cochlea stained with syntaxin ( green) and phalloidin $(r e d)$ show syntaxin as well as phalloidin reactivity, indicating that presynaptic efferent terminal membrane components are still attached. $D$, Extruded hair cells in a sound-damaged cochlea double-labeled for syntaxin and phalloidin show both markers. Scale bar, $10 \mu \mathrm{m}$. 
Figure 8. Phalloidin versus synapsin reactivity at $10 \mathrm{~d}$ and $28 \mathrm{~d}$ AOI. $A$, Phalloidin reactivity at $10 \mathrm{~d}$ AOI shows small stereocilia bundles scattered throughout the area of complete hair cell loss. The junctional complexes reveal the variability in surface area of these regenerating hair cells. Phalloidin staining is very weak at this time; increasing the sensitivity of the confocal microscope to detect this staining allows detection also of some bleed-through FITC fluorescence (the bright spots scattered throughout the image). (This permits visualization of the relationship between synapsin-reactive blobs and new hair cells. Note that the scale of this image is the same as that of the other images in this figure.) $B$, Synapsin reactivity in the region corresponding to $A$ shows numerous small blobs as well as staining of nerve fibers, some of which are indicated by arrowheads. $C$, Phalloidin reactivity within the region of complete hair cell loss at $28 \mathrm{~d}$ AOI shows numerous stereocilia bundles that are beginning to show the elongated arrays seen in control samples. The junctional complex staining outlines hair cell surface areas that are generally larger than those seen at $10 \mathrm{~d}$ AOI but still show variability in size. $D$, Synapsin reactivity in the same area as in $C$ shows a mixture of small rounded blobs and cup-like or dumbbell-shaped profiles. Staining of fibers (arrowheads) is also seen in the $28 \mathrm{~d}$ samples. E, Phalloidin reactivity at the inferior edge and $50 \%$ of the length from the proximal end of the same BP shown in $C$, distal to the region damaged by gentamycin, reveals stereocilia arrays and junctional complexes that were not damaged. Stereocilia bundles are approximately the same size as those of the regenerated hair cells in $C$, although their orientation is more regular and the phalloidin staining of junctional complexes is more compact than that in the damaged region. $F$, Synapsin reactivity in the same area in $E$ shows larger cup-like or dumbbell-shaped profiles, similar to those seen at $25 \%$ of the length in undamaged controls (Fig. 2A,E), and no staining of nerve fibers. Scale bar, $10 \mu \mathrm{m}$.
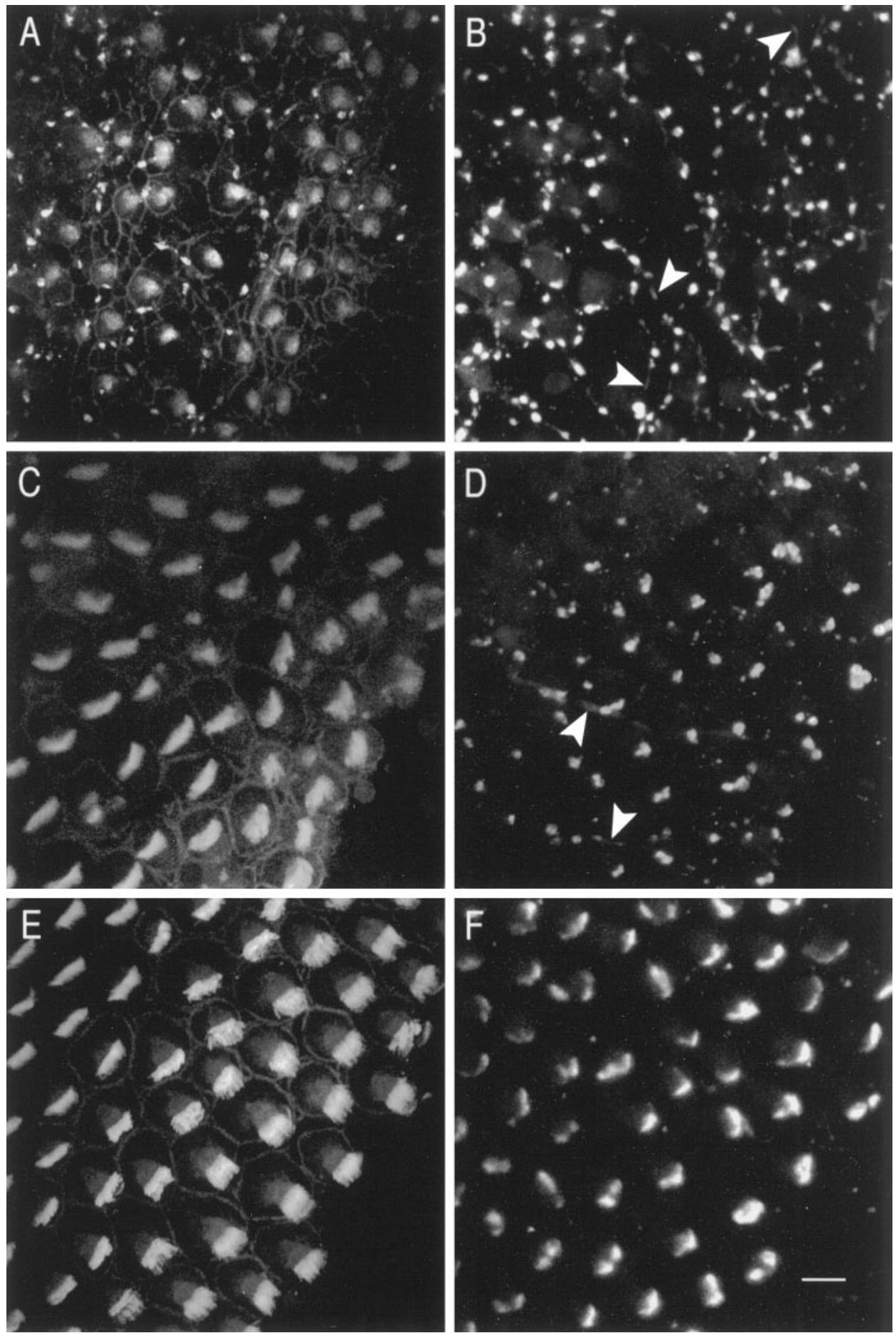

irregular, the hair cell surface areas resemble those seen in adjacent, undamaged areas of the BP (Fig. $8 C, E$ ) and in undamaged cochleae $\left(137.0 \pm 9.0\right.$ vs $132.8 \pm 3.5 \mu \mathrm{m}^{2}$ for controls; Fig. 3). However, comparison of the coefficients of variation for $28 \mathrm{~d}$ AOI samples with those of controls shows the range to be significantly wider $(p<0.016)$. This has been further examined by evaluating histograms of the ranges of hair cell surface areas (data not shown). Tukey honest siginificant difference post hoc tests reveal significant differences between controls and $28 \mathrm{~d}$ samples in the number of cells with surface areas $<100 \mu \mathrm{m}^{2}(p<$ $0.05)$ or $>160 \mu \mathrm{m}^{2}(p<0.01)$. Thus, the relative frequencies of the smallest and largest hair cells are increased in the $28 \mathrm{~d}$ samples compared with the controls, even though the mean surface area values are not significantly different. Similar findings have been reported by Duckert and Rubel (1993) in a sEM study using longer gentamycin exposures.

Hair cell density is significantly reduced in $28 \mathrm{~d}$ AOI samples (46.6 \pm 4.4$)$ compared with controls $(70.4 \pm 2.9)$ and is not statistically different from day 10 samples (Fig. 3), suggesting that initiation of most hair cell regeneration takes place shortly after damage rather than continuously throughout the regeneration period. However, if confocal images are examined at higher 
magnification, a few very small stereocilia bundles $(3.14 \pm 0.01$ per hundred hair cells), reminiscent of newly erupted hair cells, are found scattered throughout the damaged region at $28 \mathrm{~d}$ AOI. These tiny hair cells may reflect a mechanism for adjusting the number of regenerated hair cells to the normal level.

Synapsin staining within the damaged area in $28 \mathrm{~d}$ samples shows a mixture of small rounded blobs and triangular cupshaped structures (Fig. 8D), as well as label in some nerve fibers. Although the increase in cup-shaped endings in $28 \mathrm{~d}$ samples is significant compared with the levels in the day 10 samples $(15.0 \pm$ 3.5 vs $5.5 \pm 1.0$, respectively; $p<0.05$; Fig. 3 ), hair cells still outnumber cup-shaped terminals three to one at $28 \mathrm{~d}$ AOI. The number of small blob profiles at $28 \mathrm{~d}$ AOI shows a further slight decrease from the $10 \mathrm{~d}$ AOI samples $(53.0 \pm 4.4$ vs $81.2 \pm 6.9$, respectively; $p<0.05$; Fig. 3). The blob structures cannot be distinguished from bouton-type terminals on the basis of synapsin reactivity alone; so some blobs may represent synaptic terminal boutons on the regenerating hair cells. This interpretation is supported by the finding of syntaxin reactivity in small boutonlike profiles as well as in fibers at this time (data not shown).

The presence of a few hair cells with small stereocilia bundles among the more mature-appearing hair cells at $28 \mathrm{~d}$ AOI suggests that hair cell density within the damaged area may be adjusted late in the regeneration period via the addition of a few new hair cells. When day 60 AOI samples are examined (Fig. 9), a significant increase in the number of stereocilia bundles is seen compared with the $28 \mathrm{~d}$ samples $(67.2 \pm 3.1$ vs $46.6 \pm 4.4$, respectively; $p<0.01$; Fig. 3), providing further support for this conjecture. At $60 \mathrm{~d}$ AOI, the number of hair cells in the standard area is, in fact, slightly higher than that in age-matched control birds $(67.2 \pm 3.1$ vs $52.7 \pm 6.1$, respectively; $p<0.068)$, likely as a consequence of smaller surface areas $(94.0 \pm 4.7$ vs $163.0 \pm 8.1$, respectively; $p<$ 0.001 ; Fig. 3). In contrast, the number of cup-like endings at $60 \mathrm{~d}$ AOI is still markedly decreased $(26.8 \pm 4.2$ vs $52.7 \pm 6.5$, respectively; $p<0.017$ ), and the number of blobs is markedly increased compared with the levels in age-matched controls (68.0 \pm 6.0 vs $1.7 \pm 0.9$, respectively; $p<0.001$; Fig. 3$)$, indicating that the efferent terminals have not recovered their original morphology. Neither the number of cup-like endings nor the number of blobs differs significantly from the $28 \mathrm{~d}$ AOI values. As in earlier samples, some of the blobs are probably bouton-type connections on the new hair cells. Syntaxin staining shows terminal structures somewhat larger than those seen with synapsin (Fig. $9 H$ vs $D$ ), but the rounded outline also suggests bouton-type terminals rather than the cup-like shape seen in comparable regions of undamaged cochleae (Fig. 9B,F). Thus, although hair cell density appears to have reached control levels by $60 \mathrm{~d}$ AOI, neither hair cells nor efferent terminals have yet regained normal morphology.

These findings show that the repair of efferent terminals is slower after gentamycin than after sound damage. One interpretation is that repair of efferent terminals is slowed when components remain in the $\mathrm{BP}$, possibly still connected to the neuronal cell body, rather than when the terminal is completely severed from the cell body. However, it is also possible that gentamycin is acting directly on the efferent neurons as well as damaging hair cells. Efferent collaterals synapse on the hyaline cells that border the inferior edge of the basilar papilla (Keppler et al., 1994; Frisancho et al., 1997). These bouton-type synapses are also labeled with anti-synapsin (Zidanic and Fuchs, 1996; Frisancho et al., 1997) and anti-syntaxin (data not shown). Because neither the hyaline cell synapses adjacent to the gentamycin-damaged area nor efferent terminals on short hair cells lacking signs of gentamycin damage show changes in staining patterns after gentamycin treatment, direct gentamycin damage of the nerve terminals is unlikely. Furthermore, short hair cells exhibiting early signs of damage are associated with relatively normal cup-like, synapsinreactive structures in both the present studies and those of Wang and Raphael (1996), suggesting that the change in efferent terminal structure is caused by loss of the attached hair cell rather than by the damaging stimulus itself. However, it is possible that gentamycin is taken up by compromised nerve endings on damaged hair cells and delays terminal repair by metabolic interference (Wang et al., 1984). To address this possibility, we have examined cochleae from chicks exposed to both acoustic overstimulation and gentamycin. A $48 \mathrm{hr}$ exposure to a $900 \mathrm{~Hz}, 122.3$ $\mathrm{dB}$ pure tone causes a loss of short hair cells in a crescent-shaped lesion centered at $\sim 50 \%$ of the length at the inferior edge of the BP, primarily outside the area damaged by gentamycin (Fig. 10). Aminoglycosides are present throughout inner ear fluids, so they would be accessible to cells all along the length of the cochlea (Dulon et al., 1986; Fikes et al., 1994). The sensitivity of hair cells at the proximal end is attributed to membrane structural differences and/or differential expression of gentamycin receptors rather than to a drug concentration gradient (Wang et al., 1984; Richardson and Russell, 1991; Forge and Richardson, 1993; Fikes et al., 1994; Hashino and Shero, 1995). Therefore, if gentamycin directly delays repair and reconnection of efferent terminals, we would expect to see a slower reappearance of synapsin reactivity in the sound-damaged area compared with that in samples from birds that had been sound-exposed in parallel but had not received gentamycin.

Treatment with gentamycin did not appear to increase the extent of the sound-damaged lesion. In two of the birds exposed to both damage stimuli, the gentamycin-damaged area extended further than usual distally, overlapping with the sound-damaged area. (One of these cochleae is shown in Fig. 10.) This raises the possibility that previous sound overexposure increases hair cell sensitivity to gentamycin. However, lesions of similar extent are occasionally seen in birds treated with gentamycin alone.

The two birds examined $6 \mathrm{~d}$ after the onset of exposure to sound (AOE sound) and $4 \mathrm{~d}$ AOI gentamycin had numerous regenerating hair cells evident at that time within the sounddamaged area. These were recognizable by their small stereocilia bundles and apical surface areas, characteristics not found in the undamaged BP (Fig. 3) (Hennig, unpublished observations). Many regenerating hair cells were associated with small synapsinreactive structures similar to those described by Wang and Raphael (1996). The gentamycin lesions in these cochleae were indistinguishable from gentamycin-damaged lesions in chicks that had not been sound-exposed. By $12 \mathrm{~d}$ AOE sound and $10 \mathrm{~d}$ AOI gentamycin (Fig. 11), $92 \pm 6 \%$ of the regenerating hair cells in samples exposed to both sound and gentamycin had synapsinreactive structures associated with them; on $79 \pm 5 \%$ of these, the profiles were elongated or triangular in shape. In cochleae from sound-exposed birds that did not receive gentamycin, $95 \pm 2 \%$ of the regenerating hair cells were associated with synapsin-reactive profiles; $76 \pm 9 \%$ had elongated or triangular synapsin-reactive structures. At 16 d AOE sound and 14 d AOI gentamycin, $99 \pm$ $1 \%$ of the regenerating hair cells were associated with synapsin staining, and $92 \pm 2 \%$ were associated with elongated or triangular profiles, compared with $97 \pm 1 \%$ and $84 \pm 3 \%$ for samples 

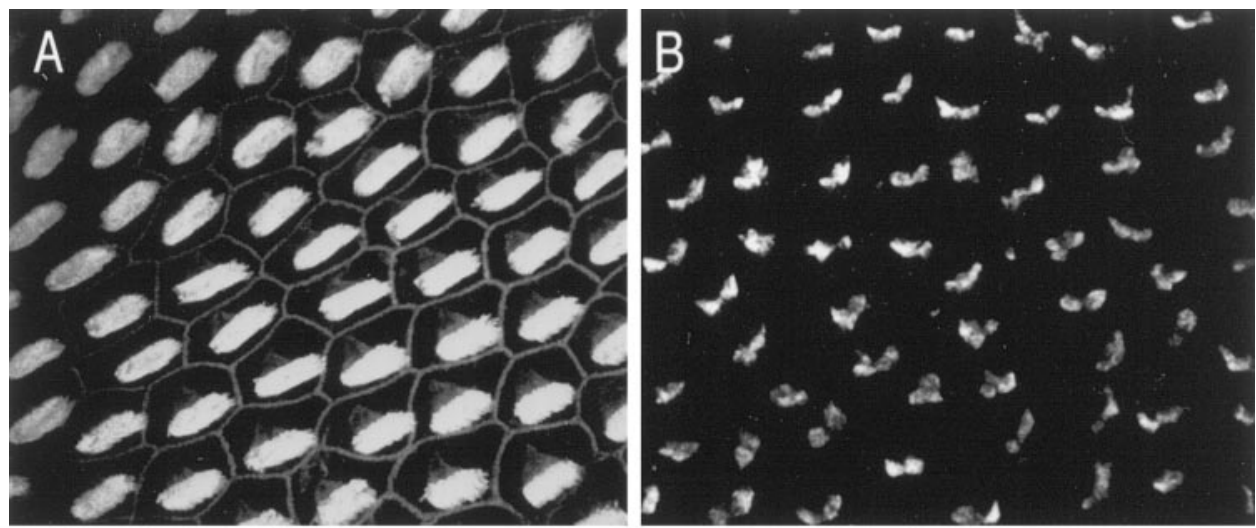

Figure 9. Phalloidin versus synapsin or syntaxin reactivity, at the inferior edge and $25 \%$ of the length from the proximal end of $60 \mathrm{~d}$ AOI gentamycin or age-matched control cochleae. $A$, Phalloidin reactivity in a control cochlea shows the regular array of hair cells. $B$, Synapsin reactivity in the same region as in $A$ shows cup-shaped terminals similar to those of younger controls (compare with Fig. $2 B$ ) and no bouton-like terminals within this region of the BP. $C$, Phalloidin reactivity in a $60 \mathrm{~d}$ AOI cochlea shows hair cells of varied sizes. $D$, Synapsin staining in the same region as in $C$ shows a mixture of small cup-shaped profiles and blobs. Although no immunoreactive fibers are seen in this image, such fibers were occasionally observed in $60 \mathrm{~d}$ AOI samples. $E$, Phalloidin reactivity in another agematched control cochlea is shown. $F$, Syntaxin reactivity in the same region as in $E$ shows broad cup-shaped profiles with some staining of neural processes. $G$, Phalloidin reactivity in another $60 \mathrm{~d}$ AOI cochlea is shown. $H$, Syntaxin reactivity in the same region in $G$ shows predominantly smaller, rounder terminal profiles than is seen in controls and more prominent fibers. Scale bar, $10 \mu \mathrm{m}$.
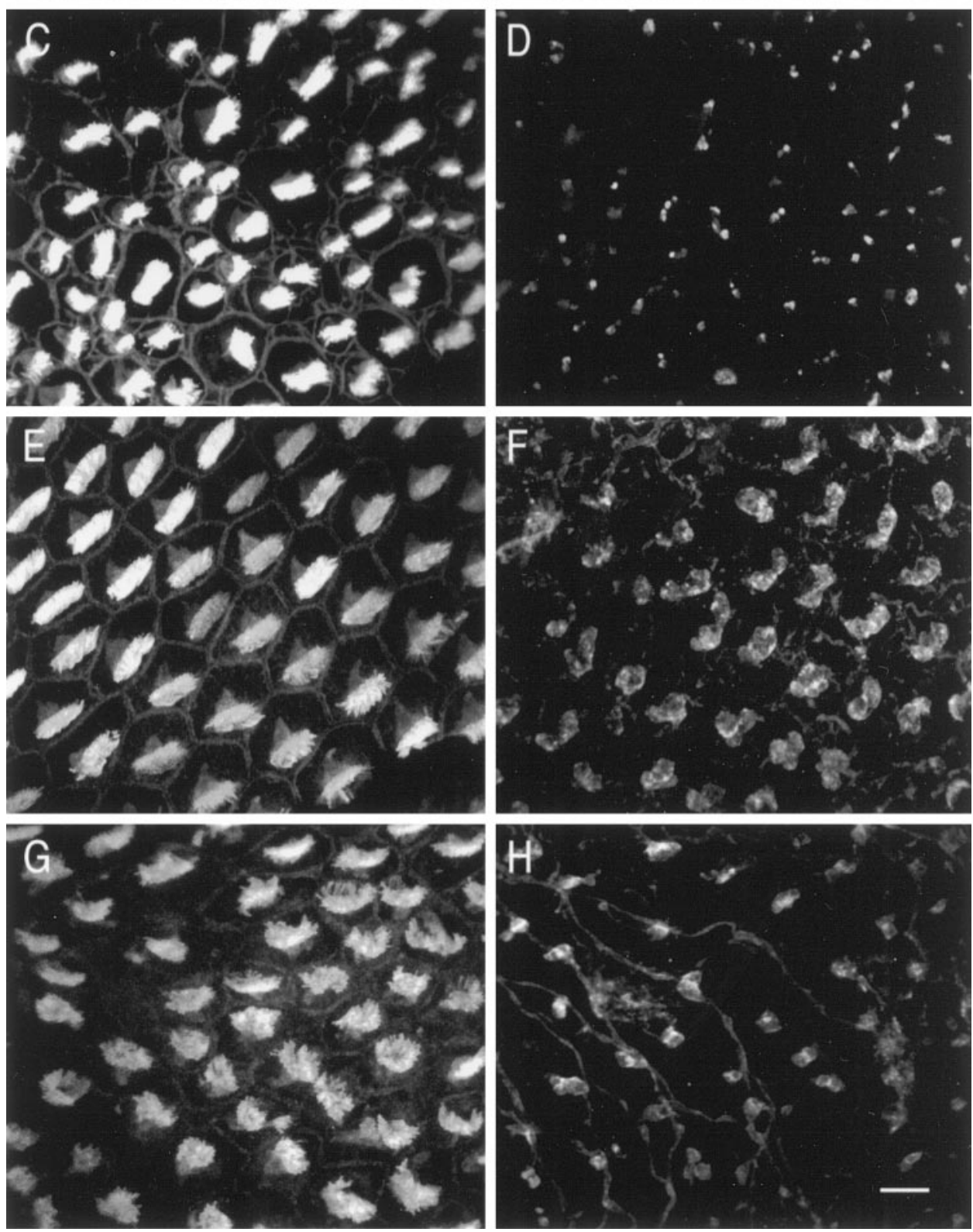

exposed to sound alone. It should be noted that some of the regenerating hair cells included in these counts were from regions innervated with bouton-type efferent contacts. Two-way ANOVA showed no significant differences with either time or treatment in the number of synapsin profiles per new hair cell. Therefore we conclude that the presence of gentamycin does not delay efferent reinnervation of regenerating hair cells after sound damage. The slower rate of recovery of cup-like efferent terminals after gentamycin damage may be related to terminal components remaining within the BP, possibly still connected to nerve fibers. 


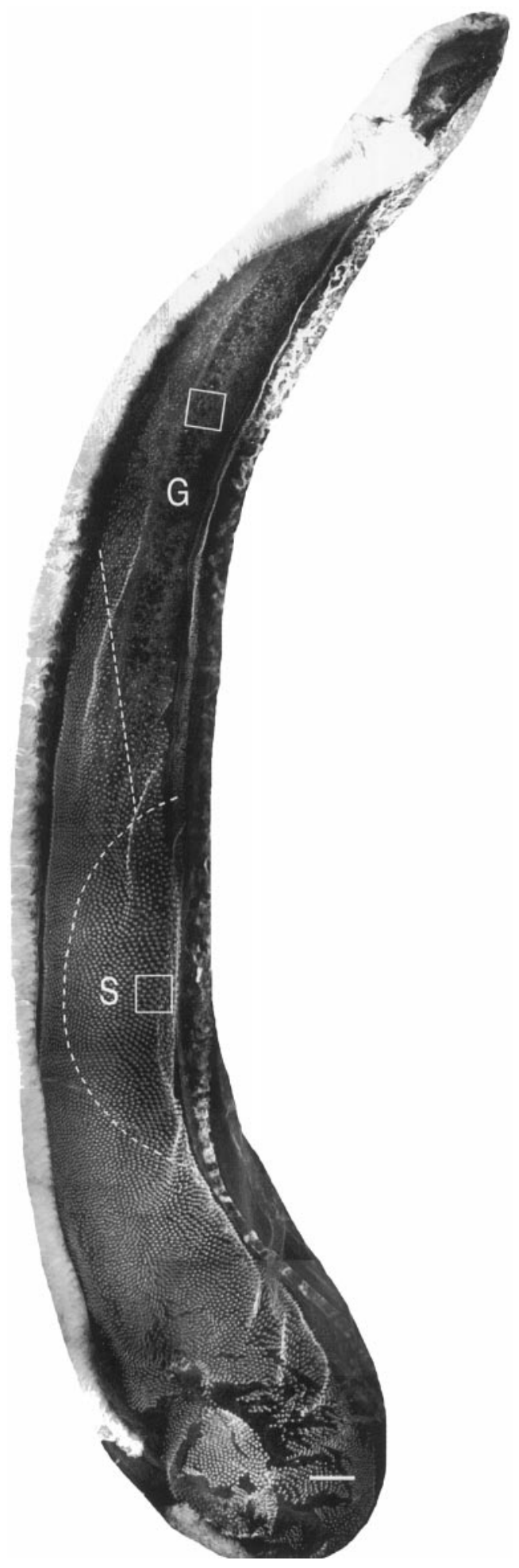

Figure 10. Composite of scans from a sample that had been sounddamaged and then exposed to gentamycin, taken $12 \mathrm{~d}$ after the initiation of sound exposure (10 d AOI gentamycin). Loss of phalloidin-reactive stereocilia bundles at the proximal end indicates the region of gentamycin damage $(G)$ at the proximal end. The sound-damaged region $(S)$ can be differentiated from undamaged areas of the BP by the widened spaces between stereocilia bundles. At higher magnification, regenerating hair cells would be apparent within this area. Boxes indicate the approximate positions of the images shown in Figure 11. Scale bar, $100 \mu \mathrm{m}$.

\section{DISCUSSION}

We have used whole-mount immunolabeling of synaptic terminal proteins to investigate efferent reinnervation in the chick cochlea during hair cell regeneration after gentamycin treatment. This technique allows three-dimensional visualization of the distribution of labeled proteins relative to other structures in the sensory epithelium and examination of changes in this distribution over time. A similar approach has been used to examine efferent reinnervation after acoustic overstimulation in the chick cochlea (Wang and Raphael, 1996). Investigating differences in recovery of innervation after sound or gentamycin damage will lead to a better understanding of axonal repair by CNS neurons in vivo. Thus, this system can further the understanding of nerve terminal regeneration and reconnection in general, as well as providing insights into the recovery of hearing associated with hair cell regeneration in avian cochleae.

The cell bodies of neurons providing efferent innervation to hair cells in chick cochleae are found in two areas within the brainstem reticular formation (Whitehead and Morest, 1981; for summary of other references, see Kaiser and Manley, 1994). Although different types of terminals are found on tall and short hair cells, it is not clear whether each hair cell population is innervated from a separate area, as in mammals (for review, see Kaiser and Manley, 1994). Fibers providing cup-like endings to short hair cells also have en passant bouton contacts on hyaline cells that border the inferior edge of the BP (Frisancho et al., 1997; Ofsie et al., 1997). These hyaline cell contacts are more resistant to sound damage than are the hair cell terminals (Frisancho et al., 1997) and so may be responsible for preventing retrograde degeneration of axons after hair cell loss (Ofsie and Cotanche, 1996). In this study, only efferent innervation of short hair cells has been investigated in detail.

As gentamycin-damaged hair cells are extruded from the BP, the large cup-shaped efferent terminals associated with short hair cells are replaced by smaller synapsin-reactive blobs. Because more than one blob appears per cup-like ending lost and synapsin reactivity remains within the $\mathrm{BP}$, whereas syntaxin reactivity is associated with extruded hair cells, this suggests that the efferent terminal breaks apart during gentamycin-induced hair cell loss. We propose a model for gentamycin-initiated damage to efferent terminals in which the presynaptic membrane remains attached to the extruded hair cell, whereas the more proximal parts of the terminal remain within the $\mathrm{BP}$ as immunoreactive blobs. This differs from sound-induced damage in which the entire terminal is extruded with the hair cell (see Fig. 7).

Partial damage of efferent terminals could produce the blob structures if the synaptic vesicle recycling machinery is preserved (Dunaevsky and Connor, 1995; Sudhof, 1995; Bauerfeind et al., 1996; Martin, 1997). Synapsin and other salvaged synaptic proteins would accumulate in fragments of terminals, nerve endings, or axonal varicosities (Lowenstein et al., 1995; NachmanClewner and Townes-Anderson, 1996). Synapsin immunoreactivity in other damage-related structures in the BP cannot be ruled out, however. Some of the immunoreactive blobs could represent ingested debris from damaged terminals within phagocytic cells (Jones and Corwin, 1993; Li et al., 1995; Warchol, 1995). Furthermore, Ide (1996) has reported the presence of synapsin I in growth cones of regenerating peripheral nerves.

In previous TEM studies after a $10 \mathrm{~d}$ course of gentamycin, efferent terminals on regenerating hair cells were not found until $17 \mathrm{~d}$ after the initiation of treatment (Duckert and Rubel, 1990). 
Figure 11. Comparison of gentamycinand sound-damaged lesions $12 \mathrm{~d}$ after the onset of sound exposure. $A$, Phalloidin staining within the gentamycindamaged area from a bird exposed to both sound and gentamycin is shown. At $12 \mathrm{~d}$ after the initiation of sound exposure (10 d AOI gentamycin), the gentamycin-damaged region appears similar to comparable regions from gentamycin-damaged cochleae not exposed to sound, with regenerating hair cells with variable surface areas. $B$, Synapsin reactivity in the same region as in $A$ shows many small blobs of immunoreactivity and the absence of large cupshaped profiles. $C$, Phalloidin staining in the sound-damaged area of a sample from sound- and gentamycin-damaged cochlea at the same time point shows small regenerating hair cells interspersed among mature hair cells that survived the sound exposure. Expanded supporting cell surfaces can also be seen between the mature hair cells. $D$, Synapsin reactivity from the same region as in $C$ shows reactive profiles associated with most of the immature hair cells. Although smaller than the profiles associated with the surrounding short hair cells, some of these regenerating terminals already have an elongated or triangular profile. $E$, Phalloidin staining in the same area of a sound-exposed bird that was not exposed to gentamycin shows small regenerating hair cells interspersed among mature hair cells, some of which have damaged stereocilia bundles. $F$, Synapsin reactivity in the same area as in $E$ shows similar small immunoreactive profiles associated with the regenerating hair cells.
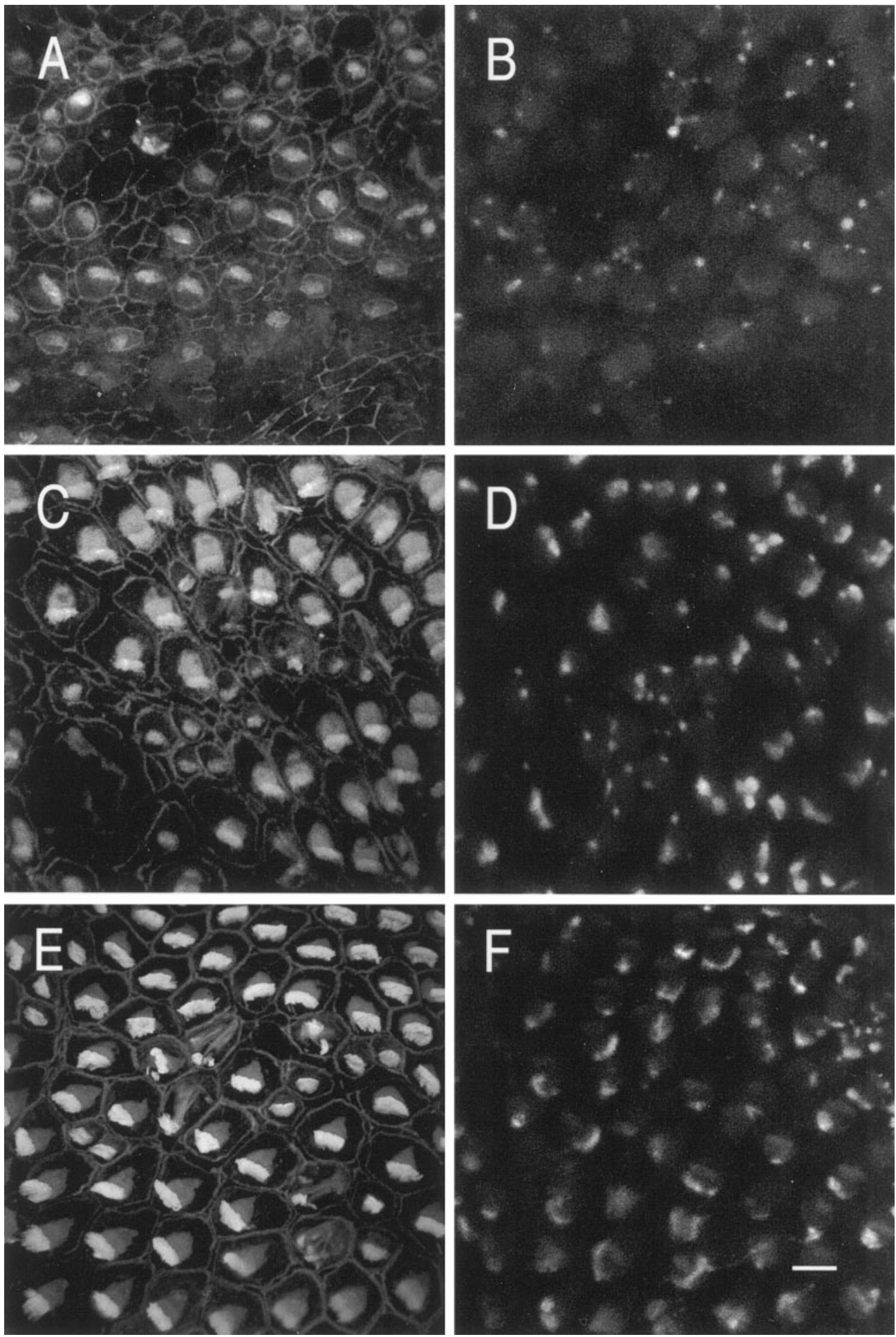

These terminals appeared as small bouton-like endings that, if they contained synapsin, would be classified in our study as blobs. Therefore, some blobs in the samples at later time points may represent bouton-type efferent contacts. Whether these progress to larger cup-like terminal structures over time is not known. Occasionally two blobs occur in close proximity, and cup-like structures that resemble the fusion of two or three blobs are seen in 28 and $60 \mathrm{~d}$ AOI samples, suggesting that such progression may be occurring.

Synapsin-labeled nerve fibers within the damaged region are seen in whole-mount preparations at all times examined, although fiber staining in undamaged areas is not observed. We have occasionally seen synapsin-labeled fibers within sound-damaged regions of the chick $\mathrm{BP}$ as well (A. K. Hennig and D. A. Cotanche, unpublished observations). Such nerve fiber reactivity in damaged areas probably reflects increased axonal transport of synaptic components. In addition to anterograde transport of newly synthesized replacement components to the terminal (Lowenstein et al., 1995; Lu et al., 1996; Nachman-Clewner and Townes-Anderson, 1996), retrograde transport of damaged syn- 
aptic components to the cell bodies within the brainstem (Ambron and Walters, 1996) could, in part, account for the decreasing number of blobs seen during regeneration.

Hair cell regeneration seems to occur in two stages after gentamycin damage. The first regenerating hair cells appear between 4 and $10 \mathrm{~d}$ AOI. A second "wave" of new hair cells arising between 28 and $60 \mathrm{~d}$ AOI increases the hair cell density to control levels. Whether these late-appearing hair cells arise from ongoing proliferation of supporting cells, via delayed differentiation of a population of uncommitted progeny from the initial proliferation, or by transdifferentiation of supporting cells (Baird et al., 1996; Roberson et al., 1996) is not known. The full complement of cup-like efferent terminals is not completely restored by $60 \mathrm{~d}$ AOI, the latest time point examined in these studies, consistent with the protracted functional recovery reported after aminoglycoside damage (Tucci and Rubel, 1990; Girod et al., 1991; Marean et al., 1993).

We have shown that the presence of gentamycin does not retard the reappearance of efferent endings on short hair cells in sound-damaged lesions. The timing of this reappearance is consistent with the onset of synapsin expression during embryonic development and in neuronal cultures (Fletcher et al., 1994; Lowenstein et al., 1995; Lu et al., 1996), as would be expected after complete loss of terminal neuronal processes. However, the restoration of large cup-like terminals is delayed after gentamycin damage, even though synapsin (and presumably also other components of the efferent terminals) remains within the BP in a form that may still be accessible to the neuronal soma. Cup-shaped synapsin-reactive terminals do not appear until the surface areas of the regenerating hair cells are approaching control values, i.e., between 10 and $28 \mathrm{~d}$ AOI. After sound damage, however, terminals appear within 9 to $12 \mathrm{~d}$ on new hair cells that show substantially smaller stereocilia bundles and apical surface areas than the surrounding undamaged hair cells (Wang and Raphael, 1996, their Fig. 3). Thus, whether elapsed time or hair cell maturity is used as the basis for comparison, a delay in reestablishing cupshaped terminals is seen after gentamycin-induced damage compared with sound overexposure. This may indicate a longer time required to synthesize the terminal structure itself or for the regenerating hair cells to mature sufficiently to receive axonal contact. The latter seems unlikely because both hair cell surface area and stereociliary bundle differentiation follow similar time courses over the first $10 \mathrm{~d}$ after gentamycin treatment and after sound damage (Cotanche, 1987; this study). Thus, the timing of hair cell differentiation is probably not the basis for the delayed development of the cup-like efferent terminals.

A bouton-type terminal, indistinguishable from a damaged terminal fragment in these studies, is the initial efferent structure innervating regenerating hair cells after gentamycin damage (Duckert and Rubel, 1990). Although there is no information available on whether the initial bouton terminals coalesce and/or expand to become cup-like, the general decrease in blobs and increase in cup-like structures is consistent with such a conversion process. The plateau in the number of blobs between 28 and $60 \mathrm{~d}$ AOI corresponds with the appearance of the second wave of new hair cells that likely also have bouton-type contacts. This is also consistent with the rounded, bouton-like pattern of syntaxin reactivity seen throughout the damaged $\mathrm{BP}$ at $60 \mathrm{~d}$. However, the reappearance of immunolabeled synaptic proteins does not indicate the recovery of function of the terminal. Gentamycin blocks calcium channels (Schacht, 1986; Smith et al., 1994), and kinetic studies show the drug is not rapidly cleared from the cochlea
(Fikes et al., 1994). If synaptic activity is required for an initial bouton-type contact to progress to a larger cup-like terminal, it is possible that residual gentamycin decreases this activity, delaying conversion of boutons to cup-like structures as well as restoration of hearing function.

It has been hypothesized that the delay in functional recovery after aminoglycoside ototoxicity results from the extensive loss of tall hair cells (McFadden and Saunders, 1989). However, the studies presented here show differences in damage and repair of efferent terminals on short hair cells after gentamycin compared with sound exposure. The protracted recovery of these terminals in the cochleae of chicks exposed to a short course of gentamycin is clearly consistent with the prolonged functional recovery times found in other studies of aminoglycoside ototoxicity. Therefore, it is likely that incomplete recovery of innervation contributes to the functional deficit. Further examination of this experimental model system to determine the basis for the delay in recovery could provide important insights into the repair mechanisms used by CNS neuronal processes, as well as providing a better understanding of the role of reinnervation of regenerated hair cells in restoring hearing function.

\section{REFERENCES}

Adler HJ, Poje CP, Saunders JC (1993) Recovery of auditory function and structure in the chick after two intense pure tone exposures. Hear Res 71:214-224.

Ambron RT, Walters ET (1996) Priming events and retrograde injury signals. A new perspective on the cellular and molecular biology of nerve regeneration. Mol Neurobiol 13:61-79.

Baird RA, Steyger PS, Schuff NR (1996) Mitotic and non-mitotic hair cell regeneration in the bullfrog vestibular otolith organs. Ann NY Acad Sci 781:59-70.

Bauerfeind R, Galli T, De Camilli P (1996) Molecular mechanisms in synaptic vesicle recycling. J Neurocytol 25:701-715.

Bennett MK, Calakos N, Scheller RH (1992) Syntaxin: a synaptic protein implicated in docking of synaptic vesicles at presynaptic active zones. Science 257:255-258.

Cotanche DA (1987) Regeneration of hair cell stereociliary bundles in the chick cochlea following severe acoustic trauma. Hear Res 30:181-196.

Cotanche DA, Sulik KK (1985) Parameters of growth in the embryonic and neonatal chick basilar papilla. Scanning Electron Microsc 1:407-417.

Cotanche DA, Saunders JC, Tilney LG (1987) Hair cell damage produced by acoustic trauma in the chick cochlea. Hear Res 25:267-286.

Cotanche DA, Lee KH, Stone JS, Picard DA (1994) Hair cell regeneration in the bird cochlea following noise damage or ototoxic drug damage. Anat Embryol (Berl) 189:1-18.

Cotanche DA, Messana EP, Ofsie MS (1995) Migration of hyaline cells into the chick basilar papilla during severe noise damage. Hear Res 91:148-159.

Cotanche DA, Hennig AK, Riedl AE, Messana EP (1997) Hair cell regeneration in the chick cochlea-where we stand after 10 years of work. In: Psychophysical and physiological advances in hearing: proceedings of the 11th International Symposium on Hearing (Palmer AR, Rees A, Summerfield AQ, Meddis A, eds), pp 109-115. London: Whurr.

Cruz RM, Lambert PR, Rubel EW (1987) Light microscopic evidence of hair cell regeneration after gentamicin toxicity in chick cochlea. Arch Otolaryngol Head Neck Surg 113:1058-1062.

Duckert LG, Rubel EW (1990) Ultrastructural observations on regenerating hair cells in the chick basilar papilla. Hear Res 48:161-182.

Duckert LG, Rubel EW (1993) Morphological correlates of functional recovery in the chicken inner ear after gentamycin treatment. J Comp Neurol 331:75-96.

Dulon D, Aran JM, Zajic G, Schacht J (1986) Comparative uptake of gentamicin, netilmicin, and amikacin in the guinea pig cochlea and vestibule. Antimicrob Agents Chemother 30:96-100.

Dunaevsky A, Connor EA (1995) Long-term maintenance of presynaptic function in the absence of target muscle fibers. J Neurosci 15:6137-6144. 
Epstein JE, Cotanche DA (1995) Secretion of a new basal layer of tectorial membrane following gentamicin-induced hair cell loss. Hear Res 90:31-43.

Eybalin M, Renard N (1997) Immunoelectron microscopy of proteins involved in synaptic vesicle release process in the guinea pig organ of Corti. Assoc Res Otolaryngol Abstr 20:210.

Fikes JD, Render JA, Reed WM, Bursian S, Poppenga RH, Sleight SD, Yoshioka T (1994) Distribution of gentamicin to the cochlea of the chicken embryo. Toxicol Pathol 22:15-22.

Fischer FP (1992) Quantitative analysis of the innervation of the chicken basilar papilla. Hear Res 61:167-178.

Fletcher TL, De Camilli P, Banker G (1994) Synaptogenesis in hippocampal cultures: evidence indicating that axons and dendrites become competent to form synapses at different stages of neuronal development. J Neurosci 14:6695-6706.

Forge A, Richardson G (1993) Freeze-fracture analysis of apical membranes in cochlear cultures: differences between basal and apical-coil outer hair cells and effects of neomycin. J Neurocytol 22:854-867.

Frisancho JC, Fritsma L, Raphael Y (1997) Presynaptic terminals in hyaline cells of normal and overstimulated chick inner ears. J Neurocytol 26:121-131.

Girod DA, Tucci DL, Rubel EW (1991) Anatomical correlates of functional recovery in the avian inner ear following aminoglucoside ototoxicity. Laryngoscope 101:1139-1149.

Greengard P, Valtorta F, Czernik AJ, Benfenati F (1993) Synaptic vesicle phosphoproteins and regulation of synaptic function. Science 259:780-785.

Hashino E, Shero M (1995) Endocytosis of aminoglycoside antibiotics in sensory hair cells. Brain Res 704:135-140.

Ide C (1996) Peripheral nerve regeneration. Neurosci Res 25:101-121.

Janas JD, Cotanche DA, Rubel EW (1995) Avian cochlear hair cell regeneration: stereological analyses of drug damage and recovery from a single high dose of gentamicin. Hear Res 92:17-29.

Jones JE, Corwin JT (1993) Replacement of lateral line sensory organs during tail regeneration in salamanders: identification of progenitor cells and analysis of leukocyte activity. J Neurosci 13:1022-1034.

Kaiser A, Manley GA (1994) Physiology of single putative cochlear efferents in the chicken. J Neurophysiol 72:2966-2979.

Katayama A (1985) Postnatal development of auditory function in the chicken revealed by auditory brainstem responses (ABRs). Electroencephalogr Clin Neurophysiol 62:388-398.

Keppler C, Schermuly L, Klinke R (1994) The course and morphology of efferent nerve fibers in the papilla basilaris of the pigeon (Columba livia). Hear Res 74:259-264.

Lee KH, Cotanche DA (1996) Localization of the hair-cell specific protein fimbrin during regeneration in the chicken cochlea. Audiol Neuro Otol 1:41-53.

Li L, Nevill G, Forge A (1995) Two modes of hair cell loss from the vestibular sensory epithelia of the guinea pig inner ear. J Comp Neurol 355:405-417.

Lowenstein PR, Shering AF, Morrison E, Thomasec P, Bain D, Jacob TJ, Wu J, Prescott A, Castro MG (1995) Synaptogenesis and distribution of presynaptic axonal varicosities in low density primary cultures of neocortex: an immunohistochemical study utilizing synaptic vesiclespecific antibodies, and an electrophysiological examination utilizing whole cell recording. J Neurocytol 24:301-317.

Lu B, Czernik AJ, Popov S, Wang T, Poo MM, Greengard P (1996) Expression of synapsin I correlates with maturation of the neuromuscular synapse. Neuroscience 74:1087-1097.

Marean GC, Burt JM, Beecher MD, Rubel EW (1993) Hair cell regen- eration in the European starling (Sturnus vulgaris): recovery of pure tone detection thresholds. Hear Res 71:125-136.

Martin TFJ (1997) Stages of regulated exocytosis. Trends Cell Biol 7:271-276.

McFadden EA, Saunders JC (1989) Recovery of auditory function following intense sound exposure in the neonatal chick. Hear Res 41:205-216.

Nachman-Clewner M, Townes-Anderson E (1996) Injury-induced remodelling and regeneration of the ribbon presynaptic terminal in vitro. J Neurocytol 25:597-613.

Ofsie MS, Cotanche DA (1996) Distribution of nerve fibers in the basilar papilla of normal and sound-damaged chick cochleae. J Comp Neurol 370:281-294.

Ofsie MS, Hennig AK, Messana EP, Cotanche DA (1997) Sound damage and gentamicin treatment produce different patterns of damage to the efferent innervation of the chick cochlea. Hear Res 113:207-223.

Richardson GP, Russell IJ (1991) Cochlear cultures as a model system for studying aminoglycoside induced ototoxicity. Hear Res 53:293-311.

Roberson DW, Krieg CS, Rubel EW (1996) Light microscopic evidence that direct transdifferentiation gives rise to new hair cells in regenerating avian auditory epithelium. Auditory Neurosci 2:195-205.

Salvi RJ, Saunders SS, Hashino E, Chen L (1994) Discharge patterns of chick cochlear ganglion neurons following kanamycin-induced hair cell loss and regeneration. J Comp Physiol [A] 174:351-369.

Saunders JC, Adler HJ, Pugliano FA (1992) The structural and functional aspects of hair cell regeneration in the chick as a result of exposure to intense sound. Exp Neurol 115:13-17.

Schacht J (1986) Molecular mechanisms of drug-induced hearing loss. Hear Res 22:297-304.

Smith DW, Erre JP, Aran JM (1994) Rapid, reversible elimination of medial olivocochlear efferent function following single injections of gentamicin in the guinea pig. Brain Res 652:243-248.

Stone JS, Cotanche DA (1992) Synchronization of hair cell regeneration in the chick cochlea following noise damage. J Cell Sci 102:671-680.

Sudhof TC (1995) The synaptic vesicle cycle: a cascade of proteinprotein interactions. Nature 375:645-653.

Tanaka K, Smith CA (1978) Structure of the chicken's inner ear: SEM and TEM study. Am J Anat 153:251-272.

Tilney LG, Tilney MS, Saunders JC, DeRosier DJ (1986) Actin filaments, stereocilia and hair cells of the bird cochlea. III. The development and differentiation of hair cells and stereocilia. Dev Biol 116:100-118.

Tucci DL, Rubel EW (1990) Physiologic status of regenerated hair cells in the avian inner ear following aminoglycoside ototoxicity. Otolaryngol Head Neck Surg 103:443.

Wang BM, Weiner ND, Takada A, Schacht J (1984) Characterization of aminoglycoside-lipid interactions and development of a refined model for ototoxicity testing. Biochem Pharmacol 33:3257-3262.

Wang Y, Raphael Y (1996) Re-innervation patterns of chick auditory sensory epithelium after acoustic overstimulation. Hear Res 97:11-18.

Warchol ME (1995) Macrophages are recruited to hair cell lesions in the avian cochlea. Assoc Res Otolaryngol Abstr 18:331.

Whitehead MC, Morest DK (1981) Dual populations of efferent and afferent cochlear axons in the chicken. Neuroscience 6:2351-2365.

Whitehead MC, Morest DK (1985) The growth of cochlear fibers and the formation of their synaptic endings in the avian inner ear. Neuroscience 14:277-300.

Zidanic M, Fuchs PA (1996) Synapsin-like immunoreactivity in the chick cochlea: specific labeling of efferent nerve terminals. Auditory Neurosci 2:347-362. 